\title{
SUPERCONVERGENCE OF MIXED FINITE ELEMENT METHODS FOR OPTIMAL CONTROL PROBLEMS
}

\author{
YANPING CHEN
}

\begin{abstract}
In this paper, we investigate the superconvergence property of the numerical solution of a quadratic convex optimal control problem by using rectangular mixed finite element methods. The state and co-state variables are approximated by the lowest order Raviart-Thomas mixed finite element spaces and the control variable is approximated by piecewise constant functions. Some realistic regularity assumptions are presented and applied to error estimation by using an operator interpolation technique. We derive $L^{2}$ superconvergence properties for the flux functions along the Gauss lines and for the scalar functions at the Gauss points via mixed projections. Moreover, global $L^{2}$ superconvergence results are obtained by virtue of an interpolation postprocessing technique. Thus, based on these superconvergence estimates, some asymptotic exactness a posteriori error estimators are presented for the mixed finite element methods. Finally, some numerical examples are given to demonstrate the practical side of the theoretical results about superconvergence.
\end{abstract}

\section{INTRODUCTION}

Optimal control problems [27] are playing an increasingly important role in science and engineering. They have various application backgrounds in the operation of physical, social, and economic processes. Efficient numerical methods [32] are critical for successful applications of optimal control in practical areas. With its wide range of applications in science and engineering, the finite element method is an important class of methods for optimal control problems and plays a very important role in numerical method for these problems. Many researchers have made various contributions to the finite element methods for optimal control problems. For example, they have obtained a priori error estimates (see, e.g., 17, [18, 2]), a posteriori error estimates, based on which adaptive finite element methods can be constructed (see, e.g., 25], 28], 29]), and have also obtained some recent superconvergence and postprocessing results (see, e.g., [30, 33]). Most of this research has been, however, for the standard finite element methods for optimal controls.

Received by the editor December 28, 2005 and, in revised form, June 25, 2007.

2000 Mathematics Subject Classification. Primary 49J20, 65N30.

Key words and phrases. Quadratic optimal control problems, mixed finite elements, rectangular partition, superconvergence, $L^{2}$ error estimates.

This work was supported by the Program for New Century Excellent Talents in University of China State Education Ministry NCET-04-0776, the National Science Foundation of China, the National Basic Research Program under the Grant 2005CB321703, and the Scientific Research Fund of the Hunan Provincial Education Department.

(C)2008 American Mathematical Society Reverts to public domain 28 years from publication 
In many control problems, the objective functional contains the gradient of the state variables. Thus, the accuracy of the gradient is important in numerical approximation of the state equations. Mixed finite element methods are appropriate for the state equations in such cases, since both the scalar variable and its flux variable can be approximated to the same accuracy by using such methods. In computational optimal control, mixed finite element methods are not as widely used as in engineering simulations. Also, not much work exists on theoretical analysis of these methods in the literature, let alone on their superconvergence analysis.

Recently, in [9] and [10, we obtained sharp a posteriori error estimates and a priori error estimates of mixed finite element methods for quadratic optimal control problems. A posteriori error estimates for general convex optimal control was addressed in [11. In this paper, we will prove the superconvergence of $\mathcal{O}\left(h^{1+s}\right)$ (for some $0<s \leq 1$ ) for the control with the lowest order Raviart-Thomas mixed finite elements based on rectangulation, via adopting a different interpolation operator (see [30]). We shall derive the local and global $L^{2}$ superconvergence analysis of the rectangular lowest order Raviart-Thomas mixed finite element methods by applying an operator interpolation technique. Some asymptotically exact a posteriori error estimators will be presented for the mixed finite element methods. Some numerical examples will be given to confirm the theoretical results.

Compared with related work (e.g., [30]), the present paper provides the first theoretical analysis of superconvergence properties for optimal control problems when they are discretized by mixed finite element methods. We can obtain the superconvergence of $\mathcal{O}\left(h^{1+s}\right)(0<s \leq 1)$ for the control variable which is approximated by piecewise constant functions. We develop a new technique to prove the superconvergence results under some realistic regularity assumptions by using operator interpolation. So far, such an application of the operator interpolation technique to error estimation has not been found in existing superconvergence literature.

We consider the following two dimensional elliptic optimal control problem:

$$
\min _{u \in U_{a d}}\left\{\frac{1}{2}\left\|\boldsymbol{p}-\boldsymbol{p}_{d}\right\|^{2}+\frac{1}{2}\left\|y-y_{d}\right\|^{2}+\frac{\nu}{2}\|u\|^{2}\right\}
$$

subject to the state equation

$$
\operatorname{div} \boldsymbol{p}+a_{0} y=u, \quad \boldsymbol{p}=-A(x) \operatorname{grad} y, \quad x \in \Omega,
$$

with the boundary condition

$$
y=0, \quad x \in \partial \Omega,
$$

where $\Omega$ is a rectangular domain, $\boldsymbol{p}_{d}$ and $y_{d}$ are two known functions, $\boldsymbol{p}, y$ are the state variables, $u$ is the control variable, and $\nu>0$ is fixed. We use $\|\cdot\|$ to denote the $L^{2}(\Omega)$ norm. Moreover, $U_{a d}$ denotes the admissible set of the control variable, defined for real numbers $a$ and $b$ by

$$
U_{a d}=\left\{u \in L^{2}(\Omega): \quad a \leq u \leq b \text { a.e. in } \Omega\right\} .
$$

The paper is organized as follows. In section 2, some realistic regularity assumptions are presented by using an operator interpolation technique. We construct a discretized scheme for the optimal control problem (1.1)-(1.3) by using mixed finite element methods and give its equivalent optimality conditions. Some projection operators and their approximated properties are also introduced. In section 3 , we derive the local $L^{2}$ superconvergence analysis of the rectangular lowest order 
Raviart-Thomas mixed finite element methods by applying an operator interpolation technique. In section 4 , we carry out the global $L^{2}$ superconvergence of the rectangular lowest order Raviart-Thomas mixed finite element methods. Some asymptotic exact a posteriori error estimators are presented for the mixed finite element methods. In section 5, some numerical examples are given to demonstrate our theoretical results. Finally, we give conclusions and mention some possible future work in section 6 .

Throughout the paper $C$ will denote a generic positive constant that is independent of $h$ but which will depend on the regularity of the optimal control problem (1.1)-(1.3).

\section{Mixed Methods FOR optimal CONTROL PROBlems}

In this section, we shall describe a mixed finite element discretization for the optimal control problem (1.1)-(1.3). We assume that the coefficient matrix function $A(x)=\left(a_{i j}(x)\right)$ is symmetric with $a_{i j}(x) \in W^{1, \infty}(\Omega)$, which satisfies the ellipticity condition

$$
c_{*}|\xi|^{2} \leq \sum_{i, j=1}^{2} a_{i j}(x) \xi_{i} \xi_{j}, \quad \forall(\xi, x) \in \mathbb{R}^{2} \times \bar{\Omega}, \quad c_{*}>0 .
$$

We require the data in the control problem to satisfy sufficient regularity.

Next, we introduce the co-state elliptic equation

$$
\operatorname{div} \boldsymbol{q}+a_{0} z=y-y_{d}, \quad \boldsymbol{q}=-A(x)\left(\operatorname{grad} z+\boldsymbol{p}-\boldsymbol{p}_{d}\right), \quad x \in \Omega,
$$

with the boundary condition

$$
z=0, \quad x \in \partial \Omega \text {. }
$$

In general, one can expect the following regularity results for the convex polygonal domain.

Lemma 2.1. If $\Omega$ is a convex polygonal domain, let the state variable $y$ and the co-state variable $z$ be the variational solutions of the elliptic problem (1.2)-(1.3) and the elliptic problem (2.1)-(2.2), respectively. Then, there exists $0<s_{0} \leq 1$ such that for $0<s<s_{0}$,

$$
\begin{aligned}
\|y\|_{H^{2+s}(\Omega)} & \leq C(s)\|u\|_{H^{s}(\Omega)}, \\
\|z\|_{H^{2+s}(\Omega)} & \leq C(s)\|y\|_{H^{s}(\Omega)} .
\end{aligned}
$$

It is known (see, e.g., 3 and [13]) that $s_{0}=\min \{1, \pi / \omega-1\}$ when both the state equation and the co-state equation are a Laplace equation and $\omega$ is the radian measure of the largest corner of the domain $\Omega(\omega<\pi)$. If the state equation and the co-state equation are variable coefficient equations, then $s_{0}$ is dependent on $\omega$ and the eigenvalue of the coefficient matrix $A(x)$ at the corner points. Some regularity analysis of elliptic problems with variable coefficients on polygonal domains are provided in [19, 21]. A special finite element method was proposed [19, 22] which has local refinement property and optimal error estimates by introducing a proper transformation of variables. Superconvergence and extrapolation are considered in [19, 20.

Thus, we make the following realistic assumption on the regularity of the solution of the optimal control problem (1.1)-(1.3) and the co-state problem (2.1)-(2.2):

$$
u \in W^{1, \infty}(\Omega), \quad y, z \in H^{2+s}(\Omega),
$$


for $0<s \leq 1$. The operator interpolation technique will be used to obtain superconvergence results under the realistic regularity assumptions (2.5).

Let

$$
\boldsymbol{V}=H(\operatorname{div} ; \Omega)=\left\{\boldsymbol{v} \in\left(L^{2}(\Omega)\right)^{2}, \operatorname{div} \boldsymbol{v} \in L^{2}(\Omega)\right\}, \quad W=L^{2}(\Omega) .
$$

The Hilbert space $\boldsymbol{V}$ is equipped with the following norm:

$$
\|\boldsymbol{v}\|_{\text {div }}=\left(\|\boldsymbol{v}\|^{2}+\|\operatorname{div} \boldsymbol{v}\|^{2}\right)^{1 / 2} .
$$

Then, the weak formulation of the optimal control problem (1.1)-(1.3) is to find $(\boldsymbol{p}, y, u) \in \boldsymbol{V} \times W \times U_{a d}$ such that

$$
\begin{aligned}
& \min _{u \in U_{a d}}\left\{\frac{1}{2}\left\|\boldsymbol{p}-\boldsymbol{p}_{d}\right\|^{2}+\frac{1}{2}\left\|y-y_{d}\right\|^{2}+\frac{\nu}{2}\|u\|^{2}\right\}, \\
& \left(A^{-1} \boldsymbol{p}, \boldsymbol{v}\right)-(y, \operatorname{div} \boldsymbol{v})=0, \quad \forall \boldsymbol{v} \in \boldsymbol{V}, \\
& (\operatorname{div} \boldsymbol{p}, w)+\left(a_{0} y, w\right)=(u, w), \quad \forall w \in W,
\end{aligned}
$$

where the inner product in $L^{2}(\Omega)$ or $\left(L^{2}(\Omega)\right)^{2}$ is denoted by $(\cdot, \cdot)$. It is well-known (see, e.g., [27]) that the convex control problem (2.6) -(2.8) has a unique solution $(\boldsymbol{p}, y, u)$, and that a triplet $(\boldsymbol{p}, y, u)$ is the solution of (2.6)-(2.8) if and only if there exists a co-state $(\boldsymbol{q}, z) \in \boldsymbol{V} \times W$ such that $(\boldsymbol{p}, y, \boldsymbol{q}, z, u)$ satisfies the following optimality conditions:

$$
\begin{array}{ll}
\left(A^{-1} \boldsymbol{p}, \boldsymbol{v}\right)-(y, \operatorname{div} \boldsymbol{v})=0, & \forall \boldsymbol{v} \in \boldsymbol{V}, \\
(\operatorname{div} \boldsymbol{p}, w)+\left(a_{0} y, w\right)=(u, w), & \forall w \in W, \\
\left(A^{-1} \boldsymbol{q}, \boldsymbol{v}\right)-(z, \operatorname{div} \boldsymbol{v})=-\left(\boldsymbol{p}-\boldsymbol{p}_{d}, \boldsymbol{v}\right), & \forall \boldsymbol{v} \in \boldsymbol{V}, \\
(\operatorname{div} \boldsymbol{q}, w)+\left(a_{0} z, w\right)=\left(y-y_{d}, w\right), & \forall w \in W, \\
(z+\nu u, \tilde{u}-u) \geq 0, & \forall \tilde{u} \in U_{a d} .
\end{array}
$$

Introducing the projection ([30])

$$
\Pi_{[a, b]}(f(x))=\max (a, \min (b, f(x)))
$$

from above optimality condition (2.13) and Remark 3 in [8], we have that

$$
u(x)=\Pi_{[a, b]}\left(-\frac{1}{\nu} z\right) .
$$

Let $\mathcal{T}_{h}$ denote a regular (in the sense of [12]) rectangular partition of the domain $\Omega$, where $\boldsymbol{V}_{h} \times W_{h} \subset \boldsymbol{V} \times W$ denotes the order $k$ Raviart-Thomas mixed finite element space 31]. To approximate the control, we use the following space of piecewise constant functions:

$$
U_{h}=\left\{\tilde{u}_{h} \in U_{a d}:\left.\quad \tilde{u}_{h}\right|_{T}=\text { constant }, \quad T \in \mathcal{T}_{h}\right\} .
$$

Before the mixed finite element scheme is given, we introduce the following Raviart-Thomas projection (see [14] and 31]):

$$
\Pi_{h} \times P_{h}: \boldsymbol{V} \times W \rightarrow \boldsymbol{V}_{h} \times W_{h},
$$

which has the following properties:

(i) $P_{h}$ is the local $L^{2}(\Omega)$ projection. 
(ii) $\Pi_{h}$ and $P_{h}$ satisfy

$$
\begin{gathered}
\operatorname{div} \circ \Pi_{h}=P_{h} \circ \operatorname{div}, \\
\left(\operatorname{div}\left(\boldsymbol{v}-\Pi_{h} \boldsymbol{v}\right), w_{h}\right)=0, \quad w_{h} \in W_{h}, \\
\left(\operatorname{div} \boldsymbol{v}_{h}, w-P_{h} w\right)=0, \quad \boldsymbol{v}_{h} \in \boldsymbol{V}_{h} .
\end{gathered}
$$

(iii) The following approximation properties hold (see [14] and [23]):

$$
\begin{array}{ll}
\left\|\boldsymbol{v}-\Pi_{h} \boldsymbol{v}\right\|_{0, \rho} \leq C h^{r}\|\boldsymbol{v}\|_{r, \rho}, & \frac{1}{\rho}<r \leq k+1, \\
\left\|\operatorname{div}\left(\boldsymbol{v}-\Pi_{h} \boldsymbol{v}\right)\right\|_{-t} \leq C h^{r+t}\|\operatorname{div} \boldsymbol{v}\|_{r}, & 0 \leq r, t \leq k+1, \\
\left\|w-P_{h} w\right\|_{-t, \rho} \leq C h^{r+t}\|w\|_{r, \rho}, & 0 \leq r, t \leq k+1,
\end{array}
$$

where $\|\cdot\|_{r, \rho}$ denotes the norm of the usual Sobolev space $W^{r, \rho}(\Omega)$ for $1 \leq \rho \leq+\infty$ and $r \geq 0$.

The mixed finite element approximation of (2.6)-(2.8) is to find $\left(\boldsymbol{p}_{h}, y_{h}, u_{h}\right) \in$ $V_{h} \times W_{h} \times U_{h}$ such that

$$
\begin{aligned}
& \min _{u_{h} \in U_{h}}\left\{\frac{1}{2}\left\|\boldsymbol{p}_{h}-\boldsymbol{p}_{d}\right\|^{2}+\frac{1}{2}\left\|y_{h}-y_{d}\right\|^{2}+\frac{\nu}{2}\left\|u_{h}\right\|^{2}\right\}, \\
& \left(A^{-1} \boldsymbol{p}_{h}, \boldsymbol{v}_{h}\right)-\left(y_{h}, \operatorname{div} \boldsymbol{v}_{h}\right)=0, \quad \forall \boldsymbol{v}_{h} \in \boldsymbol{V}_{h}, \\
& \left(\operatorname{div} \boldsymbol{p}_{h}, w_{h}\right)+\left(a_{0} y_{h}, w_{h}\right)=\left(u_{h}, w_{h}\right), \quad \forall w_{h} \in W_{h} .
\end{aligned}
$$

The control problem (2.22)-(2.24) again has a unique solution $\left(\boldsymbol{p}_{h}, y_{h}, u_{h}\right)$, and a triplet $\left(\boldsymbol{p}_{h}, y_{h}, u_{h}\right) \in \boldsymbol{V}_{h} \times W_{h} \times U_{h}$ is the solution of (2.22)-(2.24) if and only if there is a co-state $\left(\boldsymbol{q}_{h}, z_{h}\right) \in \boldsymbol{V}_{h} \times W_{h}$ such that $\left(\boldsymbol{p}_{h}, y_{h}, \boldsymbol{q}_{h}, z_{h}, u_{h}\right)$ satisfies the following discretized optimality conditions:

$$
\begin{array}{ll}
\left(A^{-1} \boldsymbol{p}_{h}, \boldsymbol{v}_{h}\right)-\left(y_{h}, \operatorname{div} \boldsymbol{v}_{h}\right)=0, & \forall \boldsymbol{v}_{h} \in \boldsymbol{V}_{h}, \\
\left(\operatorname{div} \boldsymbol{p}_{h}, w_{h}\right)+\left(a_{0} y_{h}, w_{h}\right)=\left(u_{h}, w_{h}\right), & \forall w_{h} \in W_{h}, \\
\left(A^{-1} \boldsymbol{q}_{h}, \boldsymbol{v}_{h}\right)-\left(z_{h}, \operatorname{div} \boldsymbol{v}_{h}\right)=-\left(\boldsymbol{p}_{h}-\boldsymbol{p}_{d}, \boldsymbol{v}_{h}\right), & \forall \boldsymbol{v}_{h} \in \boldsymbol{V}_{h}, \\
\left(\operatorname{div} \boldsymbol{q}_{h}, w_{h}\right)+\left(a_{0} z_{h}, w_{h}\right)=\left(y_{h}-y_{d}, w_{h}\right), & \forall w_{h} \in W_{h}, \\
\left(z_{h}+\nu u_{h}, \tilde{u}_{h}-u_{h}\right) \geq 0, & \forall \tilde{u}_{h} \in U_{h} .
\end{array}
$$

In the following analysis, we shall use some intermediate variables. For any control function $\tilde{u} \in U_{a d}$, we first define the state solution $(\boldsymbol{p}(\tilde{u}), y(\tilde{u}), \boldsymbol{q}(\tilde{u}), z(\tilde{u}))$ associated with $\tilde{u}$ which satisfies

$$
\begin{array}{ll}
\left(A^{-1} \boldsymbol{p}(\tilde{u}), \boldsymbol{v}\right)-(y(\tilde{u}), \operatorname{div} \boldsymbol{v})=0, & \forall \boldsymbol{v} \in \boldsymbol{V}, \\
(\operatorname{div} \boldsymbol{p}(\tilde{u}), w)+\left(a_{0} y(\tilde{u}), w\right)=(\tilde{u}, w), & \forall w \in W, \\
\left(A^{-1} \boldsymbol{q}(\tilde{u}), \boldsymbol{v}\right)-(z(\tilde{u}), \operatorname{div} \boldsymbol{v})=-\left(\boldsymbol{p}(\tilde{u})-\boldsymbol{p}_{d}, \boldsymbol{v}\right), & \forall \boldsymbol{v} \in \boldsymbol{V}, \\
(\operatorname{div} \boldsymbol{q}(\tilde{u}), w)+\left(a_{0} z(\tilde{u}), w\right)=\left(y(\tilde{u})-y_{d}, w\right), & \forall w \in W .
\end{array}
$$

Then, we define the discrete state solution $\left(\boldsymbol{p}_{h}(\tilde{u}), y_{h}(\tilde{u}), \boldsymbol{q}_{h}(\tilde{u}), z_{h}(\tilde{u})\right)$ corresponding to $\tilde{u}$ which satisfies

$$
\begin{aligned}
& \left(A^{-1} \boldsymbol{p}_{h}(\tilde{u}), \boldsymbol{v}_{h}\right)-\left(y_{h}(\tilde{u}), \operatorname{div} \boldsymbol{v}_{h}\right)=0, \quad \forall \boldsymbol{v}_{h} \in \boldsymbol{V}_{h}, \\
& \left(\operatorname{div} \boldsymbol{p}_{h}(\tilde{u}), w_{h}\right)+\left(a_{0} y_{h}(\tilde{u}), w_{h}\right)=\left(\tilde{u}, w_{h}\right), \quad \forall w_{h} \in W_{h}, \\
& \left(A^{-1} \boldsymbol{q}_{h}(\tilde{u}), \boldsymbol{v}_{h}\right)-\left(z_{h}(\tilde{u}), \operatorname{div} \boldsymbol{v}_{h}\right)=-\left(\boldsymbol{p}_{h}(\tilde{u})-\boldsymbol{p}_{d}, \boldsymbol{v}_{h}\right), \quad \forall \boldsymbol{v}_{h} \in \boldsymbol{V}_{h}, \\
& \left(\operatorname{div} \boldsymbol{q}_{h}(\tilde{u}), w_{h}\right)+\left(a_{0} z_{h}(\tilde{u}), w_{h}\right)=\left(y_{h}(\tilde{u})-y_{d}, w_{h}\right), \quad \forall w_{h} \in W_{h} .
\end{aligned}
$$


With these definitions, the exact state and co-state solutions and their approximation can be written as:

$$
\begin{gathered}
(\boldsymbol{p}, y, \boldsymbol{q}, z)=(\boldsymbol{p}(u), y(u), \boldsymbol{q}(u), z(u)), \\
\left(\boldsymbol{p}_{h}, y_{h}, \boldsymbol{q}_{h}, z_{h}\right)=\left(\boldsymbol{p}_{h}\left(u_{h}\right), y_{h}\left(u_{h}\right), \boldsymbol{q}_{h}\left(u_{h}\right), z_{h}\left(u_{h}\right)\right) .
\end{gathered}
$$

\section{3. $L^{2}$ SUPERCONVERGENCE ON RECTANGULAR MIXED FINITE ELEMENTS}

From now on, we assume that the coefficient $A(x)$ in the optimal control problem (1.1) -(1.3) is a diagonal matrix function. Let $\mathcal{T}_{h}=\left\{T_{i}\right\}$ be a rectangular partition of $\Omega$. In general, the partition $\mathcal{T}_{h}$ is nonuniform but regular [12. Based on this partition, we consider the lowest order $k=0$ Raviart-Thomas mixed finite element space $\boldsymbol{V}_{h} \times W_{h}$, namely,

$$
\begin{aligned}
& \boldsymbol{V}_{h}=\left\{\boldsymbol{v} \in \boldsymbol{V}: \quad \forall T_{i} \in \mathcal{T}_{h},\left.\boldsymbol{v}\right|_{T_{i}} \in Q_{1,0}\left(T_{i}\right) \times Q_{0,1}\left(T_{i}\right)\right\}, \\
& W_{h}=\left\{w \in W: \quad \forall T_{i} \in \mathcal{T}_{h},\left.w\right|_{T_{i}} \in Q_{0,0}\left(T_{i}\right)\right\},
\end{aligned}
$$

where $Q_{m, n}\left(T_{i}\right)$ indicates the space of polynomials of degree no more than $m$ and $n$ in $x$ and $y$ on $T_{i}$, respectively.

Thus, on each rectangle element $T_{i} \in \mathcal{T}_{h}$, the Gauss point is its center point $S_{i}$. For example,

$$
\text { if } T_{i}=\left[a_{i}, b_{i}\right] \times\left[c_{i}, d_{i}\right], \quad \text { then } S_{i}=\left(\left(a_{i}+b_{i}\right) / 2,\left(c_{i}+d_{i}\right) / 2\right) .
$$

As in [15], we define some semi-norms for $\boldsymbol{v}=\left(v_{1}, v_{2}\right) \in \boldsymbol{V}$ and $w \in W$ as follows:

$$
\begin{aligned}
\||w|\|_{0} & =\left(\sum_{T_{i} \in \mathcal{T}_{h}}\left|T_{i}\right| \cdot w^{2}\left(S_{i}\right)\right)^{1 / 2}, \quad\left|T_{i}\right|=\operatorname{meas}\left(T_{i}\right), \\
\left\|v_{1}\right\| \|_{1} & =\left(\sum_{T_{i} \in \mathcal{T}_{h}}\left|d_{i}-c_{i}\right| \cdot \int_{a_{i}}^{b_{i}} v_{1}^{2}\left(x_{1},\left(c_{i}+d_{i}\right) / 2\right) d x_{1}\right)^{1 / 2}, \\
\left\|\left|v_{2}\right|\right\|_{2} & =\left(\sum_{T_{i} \in \mathcal{T}_{h}}\left|b_{i}-a_{i}\right| \cdot \int_{c_{i}}^{d_{i}} v_{2}^{2}\left(\left(a_{i}+b_{i}\right) / 2, x_{2}\right) d x_{2}\right)^{1 / 2},
\end{aligned}
$$

and

$$
|||\boldsymbol{v}|||=||\left|v_{1}\right|\left\|_{1}+|| \mid v_{2}\right\|_{2} .
$$

It is clear from [15] that these semi-norms are equivalent to the $L^{2}$-norms for the functions from $\boldsymbol{V}_{h}$ and $W_{h}$, respectively.

For any smooth function $f(x) \in U_{a d}$, we define an interpolation function $f_{I} \in U_{h}$ (or $f_{I} \in W_{h}$ ):

$$
f_{I}(x)=f\left(S_{i}\right) \quad \text { if } x \in T_{i},
$$

where $S_{i}$ is the center point of the rectangle $T_{i}$. Let $f$ be a function belonging to $H^{2}\left(T_{i}\right)$ for all $i$. Then, by the Bramble-Hilbert lemma, we have [30]

$$
\left|\int_{T_{i}}\left(f(x)-f\left(S_{i}\right)\right) d x\right| \leq C h^{2} \sqrt{\left|T_{i}\right|}|f|_{H^{2}\left(T_{i}\right)}
$$

and

$$
\sum_{i}\left|\int_{T_{i}}\left(f(x)-f\left(S_{i}\right)\right) d x\right| \leq C h^{2}\left(\sum_{i}|f|_{H^{2}\left(T_{i}\right)}^{2}\right)^{1 / 2} .
$$


From the regularity assumption (2.5) and the projection formula (2.15) of $u$, we can classify the rectangles $T_{i} \in \mathcal{T}_{h}$ into two sets $K_{1}$ and $K_{2}$ :

$$
K_{1}=\left\{T_{i}: u \text { only belongs to } W^{1, \infty}\left(T_{i}\right)\right\}, \quad K_{2}=\left\{T_{i}: u \in H^{2}\left(T_{i}\right)\right\} .
$$

Clearly, the number of elements in $K_{1}$ grows for decreasing $h$. We make the following additional assumption for $K_{1}$ which is fulfilled in many practical cases (see the assumption (A3) in [30]):

$$
\operatorname{meas}\left(K_{1}\right) \leq c \cdot h .
$$

We shall prove that there exists the following superconvergence property between the interpolation function $u_{I}$ and the discrete solution $u_{h}$ of the exact control $u$. Before presenting the main theorem, we first state some known results and derive some lemmas.

Lemma 3.1. Let $z_{h}(u)$ and $z_{h}\left(u_{h}\right)$ be the discrete solutions of (2.34)-(2.37) with $\tilde{u}=u$ and $\tilde{u}=u_{h}$, respectively. Then we have

$$
\left(z_{h}\left(u_{h}\right)-z_{h}\left(u_{I}\right), u_{I}-u_{h}\right) \leq 0 .
$$

Proof. In the equations (2.34)-(2.37), we choose test functions $\tilde{u}=u_{I}$ and $\tilde{u}=u_{h}$, respectively, and get the difference equations:

$$
\begin{aligned}
& \left(A^{-1}\left(\boldsymbol{p}_{h}\left(u_{h}\right)-\boldsymbol{p}_{h}\left(u_{I}\right)\right), \boldsymbol{v}_{h}\right)-\left(y_{h}\left(u_{h}\right)-y_{h}\left(u_{I}\right), \operatorname{div} \boldsymbol{v}_{h}\right)=0, \\
& \left(\operatorname{div}\left(\boldsymbol{p}_{h}\left(u_{h}\right)-\boldsymbol{p}_{h}\left(u_{I}\right)\right), w_{h}\right)+\left(a_{0}\left(y_{h}\left(u_{h}\right)-y_{h}\left(u_{I}\right)\right), w_{h}\right)=\left(u_{h}-u_{I}, w_{h}\right), \\
& \left(A^{-1}\left(\boldsymbol{q}_{h}\left(u_{h}\right)-\boldsymbol{q}_{h}\left(u_{I}\right)\right), \boldsymbol{v}_{h}\right)-\left(z_{h}\left(u_{h}\right)-z_{h}\left(u_{I}\right), \operatorname{div} \boldsymbol{v}_{h}\right)=-\left(\boldsymbol{p}_{h}\left(u_{h}\right)-\boldsymbol{p}_{h}\left(u_{I}\right), \boldsymbol{v}_{h}\right), \\
& \left(\operatorname{div}\left(\boldsymbol{q}_{h}\left(u_{h}\right)-\boldsymbol{q}_{h}\left(u_{I}\right)\right), w_{h}\right)+\left(a_{0}\left(z_{h}\left(u_{h}\right)-z_{h}\left(u_{I}\right)\right), w_{h}\right)=\left(y_{h}\left(u_{h}\right)-y_{h}\left(u_{I}\right), w_{h}\right),
\end{aligned}
$$

for any $\boldsymbol{v}_{h} \in \boldsymbol{V}_{h}$ and $w_{h} \in W_{h}$. For above equations, we choose $w_{h}=z_{h}\left(u_{h}\right)-$ $z_{h}\left(u_{I}\right)$ in the second equation, $\boldsymbol{v}_{h}=\boldsymbol{p}_{h}\left(u_{h}\right)-\boldsymbol{p}_{h}\left(u_{I}\right)$ in the third equation, $w_{h}=$ $y_{h}\left(u_{h}\right)-y_{h}\left(u_{I}\right)$ in the fourth equation, and $\boldsymbol{v}_{h}=\boldsymbol{q}_{h}\left(u_{h}\right)-\boldsymbol{q}_{h}\left(u_{I}\right)$ in the first equation. Then we can deduce that

$$
\begin{aligned}
\left(z_{h}\left(u_{h}\right)-z_{h}\left(u_{I}\right), u-u_{h}\right) & \\
=- & \left(\operatorname{div}\left(\boldsymbol{p}_{h}\left(u_{h}\right)-\boldsymbol{p}_{h}\left(u_{I}\right)\right), z_{h}\left(u_{h}\right)-z_{h}\left(u_{I}\right)\right) \\
& -\left(a_{0}\left(y_{h}\left(u_{h}\right)-y_{h}\left(u_{I}\right)\right), z_{h}\left(u_{h}\right)-z_{h}\left(u_{I}\right)\right) \\
=- & \left(A^{-1}\left(\boldsymbol{q}_{h}\left(u_{h}\right)-\boldsymbol{q}_{h}\left(u_{I}\right)\right), \boldsymbol{p}_{h}\left(u_{h}\right)-\boldsymbol{p}_{h}\left(u_{I}\right)\right) \\
& -\left(\boldsymbol{p}_{h}\left(u_{h}\right)-\boldsymbol{p}_{h}\left(u_{I}\right), \boldsymbol{p}_{h}\left(u_{h}\right)-\boldsymbol{p}_{h}\left(u_{I}\right)\right) \\
& +\left(\operatorname{div}\left(\boldsymbol{q}_{h}\left(u_{h}\right)-\boldsymbol{q}_{h}\left(u_{I}\right)\right), y_{h}\left(u_{h}\right)-y_{h}\left(u_{I}\right)\right) \\
& -\left(y_{h}\left(u_{h}\right)-y_{h}\left(u_{I}\right), y_{h}\left(u_{h}\right)-y_{h}\left(u_{I}\right)\right) \\
\leq- & \left(A^{-1}\left(\boldsymbol{q}_{h}\left(u_{h}\right)-\boldsymbol{q}_{h}\left(u_{I}\right)\right), \boldsymbol{p}_{h}\left(u_{h}\right)-\boldsymbol{p}_{h}\left(u_{I}\right)\right) \\
& +\left(\operatorname{div}\left(\boldsymbol{q}_{h}\left(u_{h}\right)-\boldsymbol{q}_{h}\left(u_{I}\right)\right), y_{h}\left(u_{h}\right)-y_{h}\left(u_{I}\right)\right)=0,
\end{aligned}
$$

which implies (3.7).

Lemma 3.2. Assume that the regularity conditions (2.5) and (3.6) hold. Let $u_{I}$ be the interpolation of the exact control $u$ defined in (3.3) and $z\left(u_{I}\right)$ and $z(u)$ be the solutions of (2.30) $-(2.33)$ with $\tilde{u}=u_{I}$ and $\tilde{u}=u$, respectively. Then we have

$$
\left\|z\left(u_{I}\right)-z(u)\right\| \leq C\left(\|u\|_{W^{1, \infty}(\Omega)},\|z\|_{H^{2}(\Omega)}\right) h^{2}|\ln h|^{1 / 2} .
$$


Proof. From the regularity of state and co-state functions, we use the strong forms of equations (1.2) and (2.1) to obtain the error equations

$$
\begin{aligned}
& -\operatorname{div}\left(A(x) \operatorname{grad}\left(y\left(u_{I}\right)-y(u)\right)\right)+a_{0}\left(y\left(u_{I}\right)-y(u)\right)=u_{I}-u, \\
& -\operatorname{div}\left(A(x)\left(\operatorname{grad}\left(z\left(u_{I}\right)-z(u)\right)+\boldsymbol{p}\left(u_{I}\right)-\boldsymbol{p}(u)\right)\right) \\
& \quad+a_{0}\left(z\left(u_{I}\right)-z(u)\right)=y\left(u_{I}\right)-y(u),
\end{aligned}
$$

which imply that

$$
\left\|z\left(u_{I}\right)-z(u)\right\|_{H^{1}(\Omega)} \leq C\left(\left\|y\left(u_{I}\right)-y(u)\right\|+\left\|\boldsymbol{p}\left(u_{I}\right)-\boldsymbol{p}(u)\right\|\right) .
$$

Now, we multiply (3.10) by $y\left(u_{I}\right)-y(u)$ to obtain that

$$
\begin{aligned}
\| y\left(u_{I}\right) & -y(u) \|^{2} \\
= & \left(y\left(u_{I}\right)-y(u), y\left(u_{I}\right)-y(u)\right) \\
= & -\left(\operatorname{div}\left(A(x)\left(\operatorname{grad}\left(z\left(u_{I}\right)-z(u)\right)+\boldsymbol{p}\left(u_{I}\right)-\boldsymbol{p}(u)\right)\right), y\left(u_{I}\right)-y(u)\right) \\
& +\left(a_{0}\left(z\left(u_{I}\right)-z(u)\right), y\left(u_{I}\right)-y(u)\right) \\
= & \left(A(x) \operatorname{grad}\left(z\left(u_{I}\right)-z(u)\right), \operatorname{grad}\left(y\left(u_{I}\right)-y(u)\right)\right) \\
& +\left(A(x)\left(\boldsymbol{p}\left(u_{I}\right)-\boldsymbol{p}(u)\right), \operatorname{grad}\left(y\left(u_{I}\right)-y(u)\right)\right) \\
& +\left(a_{0}\left(z\left(u_{I}\right)-z(u)\right), y\left(u_{I}\right)-y(u)\right) \\
= & \left(A(x) \operatorname{grad}\left(y\left(u_{I}\right)-y(u)\right), \operatorname{grad}\left(z\left(u_{I}\right)-z(u)\right)\right) \\
& -\left(\boldsymbol{p}\left(u_{I}\right)-\boldsymbol{p}(u), \boldsymbol{p}\left(u_{I}\right)-\boldsymbol{p}(u)\right)+\left(a_{0}\left(y\left(u_{I}\right)-y(u)\right), z\left(u_{I}\right)-z(u)\right) \\
= & \left(u_{I}-u, z\left(u_{I}\right)-z(u)\right)-\left(\boldsymbol{p}\left(u_{I}\right)-\boldsymbol{p}(u), \boldsymbol{p}\left(u_{I}\right)-\boldsymbol{p}(u)\right),
\end{aligned}
$$

where we used $\boldsymbol{p}\left(u_{I}\right)-\boldsymbol{p}(u)=-A(x) \operatorname{grad}\left(y\left(u_{I}\right)-y(u)\right)$ and (3.9). Thus, we have the following identity:

$$
\left\|y\left(u_{I}\right)-y(u)\right\|^{2}+\left\|\boldsymbol{p}\left(u_{I}\right)-\boldsymbol{p}(u)\right\|^{2}=\left(u_{I}-u, z\left(u_{I}\right)-z(u)\right) .
$$

Now, we define a standard piecewise linear function space

$$
S_{h}=\left\{r_{h}(x) \in C(\bar{\Omega}): \quad r_{h} \in Q_{1,1}\left(T_{i}\right), \forall T_{i} \in \mathcal{T}_{h}\right\},
$$

and a standard $H^{1}(\Omega)$-orthogonal projection $Q_{h}: C(\bar{\Omega}) \rightarrow S_{h}$, which satisfies: for any $\psi \in C(\bar{\Omega})$

$$
\left(\operatorname{grad}\left(\psi-Q_{h} \psi\right), \operatorname{grad} r_{h}\right)=0, \quad \forall r_{h} \in S_{h} .
$$

By standard finite element analysis, the projection $Q_{h}$ has the following approximate property and stable property:

$$
\left\|\psi-Q_{h} \psi\right\| \leq C h\|\psi\|_{H^{1}(\Omega)}
$$

and

$$
\left\|Q_{h} \psi\right\|_{H^{1}(\Omega)} \leq C\|\psi\|_{H^{1}(\Omega)} .
$$

Set $r=z\left(u_{I}\right)-z(u)$ and $r_{h}=Q_{h}\left(z\left(u_{I}\right)-z(u)\right)$. We can write the right side of (3.12) as follows:

$$
\left(u_{I}-u, z\left(u_{I}\right)-z(u)\right)=\left(u_{I}-u, r-r_{h}\right)+\left(u_{I}-u, r_{h}\right) .
$$

It follows from (3.15) that

(3.18) $\left(u_{I}-u, r-r_{h}\right) \leq\left\|u_{I}-u\right\| \cdot\left\|r-r_{h}\right\| \leq C h^{2}\|u\|_{W^{1, \infty}(\Omega)} \cdot\left\|z\left(u_{I}\right)-z(u)\right\|_{H^{1}(\Omega)}$. 
We decompose the integral $\left(u_{I}-u, r_{h}\right)$ into two parts:

$$
\left(u_{I}-u, r_{h}\right)=\int_{K_{1}}\left(u_{I}-u\right) \cdot r_{h} d x+\int_{K_{2}}\left(u_{I}-u\right) \cdot r_{h} d x .
$$

Since $r_{h} \in Q_{1,1}\left(T_{i}\right)$ for any rectangle $T_{i}$, we then have

$$
\int_{T_{i}} u_{I} r_{h} d x=\int_{T_{i}} u\left(S_{i}\right) r_{h} d x=\int_{T_{i}} u\left(S_{i}\right) r_{h}\left(S_{i}\right) d x .
$$

By means of assumption (3.6) and (3.16), we obtain that

$$
\begin{aligned}
\left|\int_{K_{1}}\left(u_{I}-u\right) r_{h} d x\right| & \leq \sum_{T_{i} \in K_{1}}\left|\int_{T_{i}}\left(u\left(S_{i}\right)-u(x)\right) \cdot r_{h}(x) d x\right| \\
& \leq C \sum_{T_{i} \in K_{1}} h|u|_{1, \infty, T_{i}} \cdot\left|r_{h}\right|_{0, \infty, T_{i}} \cdot\left|T_{i}\right| \\
& \leq C h^{2}|u|_{1, \infty} \cdot\left|r_{h}\right|_{0, \infty} \leq\left. C h^{2}|u|_{1, \infty} \cdot|\ln h|^{1 / 2}|| r_{h}\right|_{H^{1}(\Omega)} \\
& \leq C h^{2}|\ln h|^{1 / 2}|| u\left\|_{W^{1, \infty}(\Omega)} \cdot\right\| z\left(u_{I}\right)-z(u) \|_{H^{1}(\Omega)} .
\end{aligned}
$$

Here, we used the well known inequality that

$$
\left\|r_{h}\right\|_{L^{\infty}(\Omega)} \leq C|\ln h|^{1 / 2}|| r_{h} \|_{H^{1}(\Omega)} .
$$

By using (3.20) and (3.5), we obtain that

$$
\begin{aligned}
\left|\int_{K_{2}}\left(u_{I}-u\right) r_{h} d x\right| & \leq \sum_{T_{i} \in K_{2}}\left|\int_{T_{i}}\left(u\left(S_{i}\right)-u(x)\right) \cdot r_{h}(x) d x\right| \\
& =\sum_{T_{i} \in K_{2}}\left|\int_{T_{i}}\left[\left(u r_{h}\right)\left(S_{i}\right)-\left(u r_{h}\right)(x)\right] d x\right| \\
& \leq C h^{2}\left(\sum_{T_{i} \in K_{2}}\left|u r_{h}\right|_{H^{2}\left(T_{i}\right)}^{2}\right)^{1 / 2} \\
& \leq C h^{2}\left(\sum_{T_{i} \in K_{2}}|u|_{H^{2}\left(T_{i}\right)}^{2} \cdot\left|r_{h}\right|_{H^{1}\left(T_{i}\right)}^{2}\right)^{1 / 2} .
\end{aligned}
$$

From (2.15), we obtain that

$$
|u|_{H^{2}\left(T_{i}\right)} \leq C|z|_{H^{2}\left(T_{i}\right)},
$$

which was discussed in [30] in detail. Applying the estimate in $H^{1}$ norm for $L^{2}$ projections (see [5]), we have

$$
\left|r_{h}\right|_{H^{1}\left(T_{i}\right)}=\left|Q_{h}\left(z\left(u_{I}\right)-z(u)\right)\right|_{H^{1}\left(T_{i}\right)} \leq C\left|z\left(u_{I}\right)-z(u)\right|_{H^{1}\left(T_{i}\right)} .
$$

Therefore,

$$
\begin{aligned}
\left|\int_{K_{2}}\left(u_{I}-u\right) r_{h} d x\right| & \leq C h^{2}\left(\sum_{T_{i} \in K_{2}}|z|_{H^{2}\left(T_{i}\right)}^{2} \cdot\left|z\left(u_{I}\right)-z(u)\right|_{H^{1}\left(T_{i}\right)}^{2}\right)^{1 / 2} \\
& \leq C h^{2} \cdot\|z\|_{H^{2}(\Omega)} \cdot\left|z\left(u_{I}\right)-z(u)\right|_{H^{1}(\Omega)} .
\end{aligned}
$$


Finally, we can combine the estimates (3.12), (3.17)-(3.19), and (3.21)-(3.23) to derive

$$
\begin{aligned}
& \left\|y\left(u_{I}\right)-y(u)\right\|^{2}+\left\|\boldsymbol{p}\left(u_{I}\right)-\boldsymbol{p}(u)\right\|^{2} \\
& \quad \leq C h^{2}|\ln h|^{1 / 2} \cdot\left\|z\left(u_{I}\right)-z(u)\right\|_{H^{1}(\Omega)} \\
& \quad \leq C h^{2}|\ln h|^{1 / 2} \cdot\left(\left\|y\left(u_{I}\right)-y(u)\right\|+\left\|\boldsymbol{p}\left(u_{I}\right)-\boldsymbol{p}(u)\right\|\right),
\end{aligned}
$$

where $C=C\left(\|u\|_{W^{1, \infty}(\Omega)},\|z\|_{H^{2}(\Omega)}\right)$, and we use the stable property (3.11) in the last step. The above inequality implies the result (3.8).

By using the standard superconvergence results of the mixed finite element methods (15, 16]), we have the following results.

Lemma 3.3. For any function $\tilde{u} \in U_{\text {ad }}$, let $(\boldsymbol{p}(\tilde{u}), y(\tilde{u}), \boldsymbol{q}(\tilde{u}), z(\tilde{u}))$ and $\left(\boldsymbol{p}_{h}(\tilde{u}), y_{h}(\tilde{u}), \boldsymbol{q}_{h}(\tilde{u}), z_{h}(\tilde{u})\right)$ be the solutions of (2.30) -(2.33) and (2.34) -(2.37), respectively, for the lowest order Raviart-Thomas mixed finite elements. If the regularity condition

$$
y(\tilde{u}), z(\tilde{u}) \in H^{1}(\Omega) \quad \boldsymbol{p}(\tilde{u}), \boldsymbol{q}(\tilde{u}) \in\left(H^{2}(\Omega)\right)^{2}
$$

holds, then we have

$$
\begin{gathered}
\left\|P_{h} y(\tilde{u})-y_{h}(\tilde{u})\right\|+\left\|\Pi_{h} \boldsymbol{p}(\tilde{u})-\boldsymbol{p}_{h}(\tilde{u})\right\| \\
\leq C h^{2}\left(\|\boldsymbol{p}(\tilde{u})\|_{H^{2}(\Omega)}+\|y(\tilde{u})\|_{H^{1}(\Omega)}\right), \\
\left\|P_{h} z(\tilde{u})-z_{h}(\tilde{u})\right\|+\left\|\Pi_{h} \boldsymbol{q}(\tilde{u})-\boldsymbol{q}_{h}(\tilde{u})\right\| \\
\leq C h^{2}\left(\|\boldsymbol{q}(\tilde{u})\|_{H^{2}(\Omega)}+\|z(\tilde{u})\|_{H^{1}(\Omega)}\right) .
\end{gathered}
$$

Lemma 3.4. Assume that the regularity condition (2.5) holds. Let $z\left(u_{I}\right)$ and $z_{h}\left(u_{I}\right)$ be the solutions of (2.30)-(2.33) and (2.34)-(2.37) with $\tilde{u}=u_{I}$, respectively. Then we have

$$
\left(z_{h}\left(u_{I}\right)-z\left(u_{I}\right), u_{I}-u_{h}\right) \leq C h^{1+s}\|z\|_{H^{2+s}(\Omega)} \cdot\left\|u_{I}-u_{h}\right\|, \quad 0<s \leq 1 .
$$

Proof. It is easy to see that

$$
\left(z_{h}\left(u_{I}\right)-z\left(u_{I}\right), u_{I}-u_{h}\right)=\left(z_{h}\left(u_{I}\right)-P_{h} z\left(u_{I}\right), u_{I}-u_{h}\right) .
$$

On the one hand, under the condition $z\left(u_{I}\right) \in H^{3}(\Omega)$, namely

$$
z\left(u_{I}\right) \in H^{1}(\Omega) \quad \boldsymbol{q}\left(u_{I}\right) \in\left(H^{2}(\Omega)\right)^{2},
$$

by applying the superconvergence result (3.26) in Lemma 3.3 with $\tilde{u}=u_{I}$, we obtain that

$$
\begin{aligned}
\left\|z_{h}\left(u_{I}\right)-P_{h} z\left(u_{I}\right)\right\| & \leq C h^{2}\left(\left\|\boldsymbol{q}\left(u_{I}\right)\right\|_{H^{2}(\Omega)}+\left\|z\left(u_{I}\right)\right\|_{H^{1}(\Omega)}\right) \\
& \leq C h^{2}\left\|z\left(u_{I}\right)\right\|_{H^{3}(\Omega)} .
\end{aligned}
$$

On the other hand, by the standard priori error estimate, we have

$$
\left\|z_{h}\left(u_{I}\right)-P_{h} z\left(u_{I}\right)\right\| \leq C h\left\|z\left(u_{I}\right)\right\|_{H^{2}(\Omega)} .
$$

It easy to see that the equations (2.34)-(2.37) define a linear operator $z\left(u_{I}\right) \longrightarrow$ $z_{h}\left(u_{I}\right)$ and $P_{h}$ defines a linear operator $z\left(u_{I}\right) \longrightarrow P_{h} z\left(u_{I}\right)$. Let $L$ be the linear operator $z\left(u_{I}\right) \longrightarrow z_{h}\left(u_{I}\right)-P_{h} z\left(u_{I}\right)$, namely

$$
L z\left(u_{I}\right)=z_{h}\left(u_{I}\right)-P_{h} z\left(u_{I}\right) .
$$


Then, by the interpolation theory in Sobolev space (see [1), it follows from (3.29)(3.30) that

$$
\begin{aligned}
\|L\|_{\mathcal{L}\left(H^{2+s}(\Omega) \rightarrow L^{2}(\Omega)\right)} & \leq\|L\|_{\mathcal{L}\left(H^{3}(\Omega) \rightarrow L^{2}(\Omega)\right)}^{s}\|L\|_{\mathcal{L}\left(H^{2}(\Omega) \rightarrow L^{2}(\Omega)\right)}^{1-s} \\
& \leq C\left(h^{2}\right)^{s} \cdot h^{1-s}=C h^{1+s}
\end{aligned}
$$

which implies

$$
\begin{aligned}
\left\|z_{h}\left(u_{I}\right)-P_{h} z\left(u_{I}\right)\right\| & =\left\|L z\left(u_{I}\right)\right\| \\
& \leq\|L\|_{\mathcal{L}\left(H^{2+s}(\Omega) \rightarrow L^{2}(\Omega)\right)} \cdot\left\|z\left(u_{I}\right)\right\|_{H^{2+s}(\Omega)} \\
& \leq C h^{1+s}\left\|z\left(u_{I}\right)\right\|_{H^{2+s}(\Omega)} \\
& \leq C h^{1+s}\|z\|_{H^{2+s}(\Omega)} .
\end{aligned}
$$

Then, the requested result (3.27) follows from (3.28) and (3.31).

Lemma 3.5. Let $u_{h}$ be the solution of (2.25) -(2.29) and $u_{I}$ and $z_{I}$ the interpolation functions of $u$ and $z$ defined in (3.3), respectively. Then we have

$$
\left(z-z_{I}, u_{I}-u_{h}\right) \leq C h^{2}\|z\|_{H^{2}(\Omega)} \cdot\left\|u_{I}-u_{h}\right\| .
$$

Proof. It follows from the regularity of the elliptic equations (1.2), (2.1), and (3.4) that

$$
\begin{aligned}
(z- & \left.z_{I}, u_{I}-u_{h}\right) \\
& =\sum_{i} \int_{T_{i}}\left(z(x)-z_{I}(x)\right) \cdot\left(u_{I}(x)-u_{h}(x)\right) d x \\
& =\sum_{i}\left(u_{I}\left(S_{i}\right)-u_{h}\left(S_{i}\right)\right) \int_{T_{i}}\left(z(x)-z\left(S_{i}\right)\right) d x \\
& \leq \sum_{i} C h^{2}\left|u_{I}\left(S_{i}\right)-u_{h}\left(S_{i}\right)\right| \sqrt{\left|T_{i}\right|} \cdot|z|_{H^{2}\left(T_{i}\right)} \\
& \leq C h^{2} \cdot|| u_{I}-u_{h}|| \cdot|z|_{H^{2}(\Omega)},
\end{aligned}
$$

which implies the estimate (3.32).

Now, we are able to derive our first main result.

Theorem 3.1. Assume that the regularity conditions (2.5) and (3.6) hold. Let $u_{I}$ be the interpolation of the exact control $u$ defined in (3.3) and $u_{h}$ be the solution of (2.25) -(2.29). Then we have the estimate

$$
\left\|u_{I}-u_{h}\right\| \leq C h^{1+s}, \quad 0<s \leq 1
$$

Proof. First, we derive a variational inequality for the function $u_{I}$. Since the relation (2.13) is true for all $\tilde{u} \in U_{a d}$, we have

$$
(z(x)+\nu u(x)) \cdot(\tilde{u}-u(x)) \geq 0, \quad \forall \tilde{u} \in[a, b], \quad \forall x \in \Omega .
$$

We apply this formula for $x=S_{i}$ and $\tilde{u}=u_{h}\left(S_{i}\right)$. This is correct because of the continuity of $u, z$, and $u_{h}$ in these points $\left\{S_{i}\right\}$. That is,

$$
\left(z\left(S_{i}\right)+\nu u\left(S_{i}\right)\right) \cdot\left(u_{h}\left(S_{i}\right)-u\left(S_{i}\right)\right) \geq 0, \quad \forall S_{i} .
$$

It follows from the definition (3.3) of $u_{I}$ that

$$
\left(z\left(S_{i}\right)+\nu u_{I}\left(S_{i}\right)\right) \cdot\left(u_{h}\left(S_{i}\right)-u_{I}\left(S_{i}\right)\right) \geq 0, \quad \forall S_{i} .
$$


We integrate this inequality over $T_{i}$ and add up over all $i$ to obtain that

$$
\left(z_{I}+\nu u_{I}, u_{h}-u_{I}\right) \geq 0 .
$$

Now, in (2.29), we choose the test function $\tilde{u}_{h}=u_{I}$ to obtain that

$$
\left(z_{h}\left(u_{h}\right)+\nu u_{h}, u_{I}-u_{h}\right) \geq 0 .
$$

By adding these two inequalities (3.34) and (3.35), we have

$$
\left(z_{h}\left(u_{h}\right)-z_{I}+\nu\left(u_{h}-u_{I}\right), u_{I}-u_{h}\right) \geq 0 .
$$

Hence,

$$
\begin{aligned}
\nu\left\|u_{I}-u_{h}\right\|^{2} \leq & \left(z_{h}\left(u_{h}\right)-z_{I}, u_{I}-u_{h}\right) \\
= & \left(z_{h}\left(u_{h}\right)-z_{h}\left(u_{I}\right), u_{I}-u_{h}\right)+\left(z_{h}\left(u_{I}\right)-z\left(u_{I}\right), u_{I}-u\right) \\
& +\left(z\left(u_{I}\right)-z(u), u_{I}-u_{h}\right)+\left(z-z_{I}, u_{I}-u_{h}\right) .
\end{aligned}
$$

Then we combine Lemma 3.1, Lemma 3.4 Lemma 3.2 and Lemma 3.5 to deduce the superconvergence result (3.33).

Furthermore, we can establish the following superconvergence result for state and co-state. But, due to the low regularity of the control, the accuracy is only of the order $h^{1+\min (s, 1 / 2)}$.

Theorem 3.2. Assume that the regularity conditions (2.5) and (3.6) hold. Let $(\boldsymbol{p}, y, \boldsymbol{q}, z, u) \in(\boldsymbol{V} \times W)^{2} \times U_{\text {ad }}$ be the exact solutions defined in (2.9) $-(2.13)$ and $\left(\boldsymbol{p}_{h}, y_{h}, \boldsymbol{q}_{h}, z_{h}, u_{h}\right) \in\left(\boldsymbol{V}_{h} \times W_{h}\right)^{2} \times U_{h}$ be the exact solutions of (2.25)-(2.29). Then we have

$$
\begin{gathered}
\left\|\Pi_{h} \boldsymbol{p}-\boldsymbol{p}_{h}\right\|_{\mathrm{div}}+\left\|P_{h} y-y_{h}\right\| \leq C h^{1+\min (s, 1 / 2)}, \\
\left\|\Pi_{h} \boldsymbol{q}-\boldsymbol{q}_{h}\right\|_{\mathrm{div}}+\left\|P_{h} z-z_{h}\right\| \leq C h^{1+\min (s, 1 / 2)}
\end{gathered}
$$

for $0<s \leq 1$.

Proof. It follows from (2.9) $-(2.12)$ and $(2.25)-(2.28)$ that we have the error equations:

$$
\begin{aligned}
& \left(A^{-1}\left(\boldsymbol{p}-\boldsymbol{p}_{h}\right), \boldsymbol{v}_{h}\right)-\left(y-y_{h}, \operatorname{div} \boldsymbol{v}_{h}\right)=0, \\
& \left(\operatorname{div}\left(\boldsymbol{p}-\boldsymbol{p}_{h}\right), w_{h}\right)+\left(a_{0}\left(y-y_{h}\right), w_{h}\right)=\left(u-u_{h}, w_{h}\right), \\
& \left(A^{-1}\left(\boldsymbol{q}-\boldsymbol{q}_{h}\right), \boldsymbol{v}_{h}\right)-\left(z-z_{h}, \operatorname{div} \boldsymbol{v}_{h}\right)=-\left(\boldsymbol{p}-\boldsymbol{p}_{h}, \boldsymbol{v}_{h}\right), \\
& \left(\operatorname{div}\left(\boldsymbol{q}-\boldsymbol{q}_{h}\right), w_{h}\right)+\left(a_{0}\left(z-z_{h}\right), w_{h}\right)=\left(y-y_{h}, w_{h}\right),
\end{aligned}
$$

for all $\boldsymbol{v}_{h} \in \boldsymbol{V}_{h}$ and $w_{h} \in W_{h}$. By using the definitions of projections $\Pi_{h}$ and $P_{h}$, the above equations can be rewritten as follows:

$$
\begin{aligned}
& \left(A^{-1}\left(\Pi_{h} \boldsymbol{p}-\boldsymbol{p}_{h}\right), \boldsymbol{v}_{h}\right)-\left(P_{h} y-y_{h}, \operatorname{div} \boldsymbol{v}_{h}\right)=\phi_{1}\left(\boldsymbol{v}_{h}\right), \\
& \left(\operatorname{div}\left(\Pi_{h} \boldsymbol{p}-\boldsymbol{p}_{h}\right), w_{h}\right)+\left(a_{0}\left(P_{h} y-y_{h}\right), w_{h}\right)=\psi_{1}\left(w_{h}\right), \\
& \left(A^{-1}\left(\Pi_{h} \boldsymbol{q}-\boldsymbol{q}_{h}\right), \boldsymbol{v}_{h}\right)-\left(P_{h} z-z_{h}, \operatorname{div} \boldsymbol{v}_{h}\right)=\phi_{2}\left(\boldsymbol{v}_{h}\right), \\
& \left(\operatorname{div}\left(\Pi_{h} \boldsymbol{q}-\boldsymbol{q}_{h}\right), w_{h}\right)+\left(a_{0}\left(P_{h} z-z_{h}\right), w_{h}\right)=\psi_{2}\left(w_{h}\right),
\end{aligned}
$$

for all $\boldsymbol{v}_{h} \in \boldsymbol{V}_{h}$ and $w_{h} \in W_{h}$, where

$$
\begin{aligned}
& \phi_{1}\left(\boldsymbol{v}_{h}\right)=-\left(A^{-1}\left(\boldsymbol{p}-\Pi_{h} \boldsymbol{p}\right), \boldsymbol{v}_{h}\right), \\
& \psi_{1}\left(w_{h}\right)=\left(u-u_{h}, w_{h}\right)-\left(a_{0}\left(y-P_{h} y\right), w_{h}\right), \\
& \phi_{2}\left(\boldsymbol{v}_{h}\right)=-\left(\boldsymbol{p}-\boldsymbol{p}_{h}, \boldsymbol{v}_{h}\right)-\left(A^{-1}\left(\boldsymbol{q}-\Pi_{h} \boldsymbol{q}\right), \boldsymbol{v}_{h}\right), \\
& \psi_{2}\left(w_{h}\right)=\left(y-y_{h}, w_{h}\right)-\left(a_{0}\left(z-P_{h} z\right), w_{h}\right) .
\end{aligned}
$$


Since the terms $\phi_{1}\left(\boldsymbol{v}_{h}\right), \psi_{1}\left(w_{h}\right), \phi_{2}\left(\boldsymbol{v}_{h}\right)$, and $\psi_{2}\left(w_{h}\right)$ can be regarded as linear functionals of $\boldsymbol{v}_{h}$ and $w_{h}$ defined on $\boldsymbol{V}_{h}$ and $W_{h}$, respectively, then we know from the stability result of [7] that

$$
\begin{aligned}
& \left\|\Pi_{h} \boldsymbol{p}-\boldsymbol{p}_{h}\right\|_{\text {div }}+\left\|P_{h} y-y_{h}\right\| \leq C\left\{\sup _{\boldsymbol{v}_{h} \in \boldsymbol{V}_{h}} \frac{\left|\phi_{1}\left(\boldsymbol{v}_{h}\right)\right|}{\left\|\boldsymbol{v}_{h}\right\|_{\text {div }}}+\sup _{w_{h} \in W_{h}} \frac{\left|\psi_{1}\left(w_{h}\right)\right|}{\| w_{h}||}\right\} \\
& \left\|\Pi_{h} \boldsymbol{q}-\boldsymbol{q}_{h}\right\|_{\text {div }}+\left\|P_{h} z-z_{h}\right\| \leq C\left\{\sup _{\boldsymbol{v}_{h} \in \boldsymbol{V}_{h}} \frac{\left|\phi_{2}\left(\boldsymbol{v}_{h}\right)\right|}{\left\|\boldsymbol{v}_{h}\right\|_{\text {div }}}+\sup _{w_{h} \in W_{h}} \frac{\left|\psi_{2}\left(w_{h}\right)\right|}{\left\|w_{h}\right\|}\right\}
\end{aligned}
$$

It is easy to see that

$$
\begin{gathered}
\left(\boldsymbol{p}-\boldsymbol{p}_{h}, \boldsymbol{v}_{h}\right)=\left(\boldsymbol{p}-\Pi_{h} \boldsymbol{p}, \boldsymbol{v}_{h}\right)+\left(\Pi_{h} \boldsymbol{p}-\boldsymbol{p}_{h}, \boldsymbol{v}_{h}\right) \\
\left(y-y_{h}, w_{h}\right)=\left(y-P_{h} y, w_{h}\right)+\left(P_{h} y-y_{h}, w_{h}\right)=\left(P_{h} y-y_{h}, w_{h}\right) .
\end{gathered}
$$

By the standard superconvergence of the mixed finite element methods, we have

$$
\begin{aligned}
& \left(a_{0}\left(y-P_{h} y\right), w_{h}\right) \leq C h^{2}\|y\|_{H^{1}(\Omega)}\left\|w_{h}\right\|, \\
& \left(a_{0}\left(z-P_{h} z\right), w_{h}\right) \leq C h^{2}\|z\|_{H^{1}(\Omega)}\left\|w_{h}\right\| .
\end{aligned}
$$

On the one hand, under the condition $y, z \in H^{3}(\Omega)$, applying the integral identity technique (26] and [15]), we see that

$$
\begin{aligned}
& \left(A^{-1}\left(\boldsymbol{p}-\Pi_{h} \boldsymbol{p}\right), \boldsymbol{v}_{h}\right) \leq C h^{2}\|y\|_{H^{3}(\Omega)}\left\|\boldsymbol{v}_{h}\right\|, \\
& \left(A^{-1}\left(\boldsymbol{q}-\Pi_{h} \boldsymbol{q}\right), \boldsymbol{v}_{h}\right) \leq C h^{2}\|z\|_{H^{3}(\Omega)}\left\|\boldsymbol{v}_{h}\right\|, \\
& \left(\boldsymbol{p}-\Pi_{h} \boldsymbol{p}, \boldsymbol{v}_{h}\right) \leq C h^{2}\|y\|_{H^{3}(\Omega)}\left\|\boldsymbol{v}_{h}\right\| .
\end{aligned}
$$

On the other hand, applying the standard error estimates of the mixed finite element methods and the approximation properties of the projection operators $P_{h}$ and $\Pi_{h}$, we have that

$$
\begin{aligned}
& \left(A^{-1}\left(\boldsymbol{p}-\Pi_{h} \boldsymbol{p}\right), \boldsymbol{v}_{h}\right) \leq C h\|y\|_{H^{2}(\Omega)}\left\|\boldsymbol{v}_{h}\right\|, \\
& \left(A^{-1}\left(\boldsymbol{q}-\Pi_{h} \boldsymbol{q}\right), \boldsymbol{v}_{h}\right) \leq C h\|z\|_{H^{2}(\Omega)}\left\|\boldsymbol{v}_{h}\right\|, \\
& \left(\boldsymbol{p}-\Pi_{h} \boldsymbol{p}, \boldsymbol{v}_{h}\right) \leq C h\|y\|_{H^{2}(\Omega)}\left\|\boldsymbol{v}_{h}\right\| .
\end{aligned}
$$

Then, by interpolation theory, under the regularity conditions (2.5), we obtain that

$$
\begin{aligned}
\left(A^{-1}\left(\boldsymbol{p}-\Pi_{h} \boldsymbol{p}\right), \boldsymbol{v}_{h}\right) & \leq C h^{1+s}\|y\|_{H^{2+s}(\Omega)}\left\|\boldsymbol{v}_{h}\right\|, \\
\left(A^{-1}\left(\boldsymbol{q}-\Pi_{h} \boldsymbol{q}\right), \boldsymbol{v}_{h}\right) & \leq C h^{1+s}\|z\|_{H^{2+s}(\Omega)}\left\|\boldsymbol{v}_{h}\right\|, \\
\left(\boldsymbol{p}-\Pi_{h} \boldsymbol{p}, \boldsymbol{v}_{h}\right) & \leq C h^{1+s}\|y\|_{H^{2+s}(\Omega)}\left\|\boldsymbol{v}_{h}\right\| .
\end{aligned}
$$

Here, we only give the proof of (3.49). We define a linear functional

$$
T y=\left(A^{-1}\left(\boldsymbol{p}-\Pi_{h} \boldsymbol{p}\right), \boldsymbol{v}_{h}\right)=\left(A^{-1}\left((-A \operatorname{grad} y)-\Pi_{h}(-A \operatorname{grad} y)\right), \boldsymbol{v}_{h}\right) .
$$

Then, it follows from (3.43) and (3.46) that

$$
\begin{aligned}
\|T\|_{\mathcal{L}\left(H^{2+s}(\Omega) \rightarrow \mathbb{R}\right)} & \leq\|T\|_{\mathcal{L}\left(H^{3}(\Omega) \rightarrow \mathbb{R}\right)}^{s}\|T\|_{\mathcal{L}\left(H^{2}(\Omega) \rightarrow \mathbb{R}\right)}^{1-s} \\
& \leq C\left(h^{2}\left\|\boldsymbol{v}_{h}\right\|\right)^{s} \cdot\left(h\left\|\boldsymbol{v}_{h}\right\|\right)^{1-s}=C h^{1+s}\left\|\boldsymbol{v}_{h}\right\|,
\end{aligned}
$$

which implies (3.49). We can similarly prove (3.50) and (3.51).

Note that

$$
\begin{aligned}
\left(u-u_{h}, w_{h}\right) & =\left(u-u_{I}, w_{h}\right)+\left(u_{I}-u_{h}, w_{h}\right) \\
& =\left(u-u_{I}, w_{h}\right)_{K_{1}}+\left(u-u_{I}, w_{h}\right)_{K_{2}}+\left(u_{I}-u_{h}, w_{h}\right) .
\end{aligned}
$$


It follows from the assumption (3.6) and (3.5) that

$$
\begin{aligned}
\left(u-u_{I}, w_{h}\right)_{K_{1}} & \leq \sum_{T_{i} \in K_{1}} \int_{T_{i}}\left|u(x)-u\left(S_{i}\right)\right| \cdot\left|w_{h}\right| d x \\
& \leq C h \sum_{T_{i} \in K_{1}}\|u\|_{1, \infty, T_{i}} \int_{T_{i}}\left|w_{h}\right| d x \\
& \leq C h\|u\|_{1, \infty} \sum_{T_{i} \in K_{1}} \sqrt{\left|T_{i}\right|} \cdot\left\|w_{h}\right\|_{T_{i}} \\
& \leq C h^{3 / 2}\|u\|_{1, \infty} \cdot\left\|w_{h}\right\|, \\
\left(u-u_{I}, w_{h}\right)_{K_{2}} & \leq \sum_{T_{i} \in K_{2}}\left|w_{h}\right| \cdot\left|\int_{T_{i}}\left(u(x)-u\left(S_{i}\right)\right) d x\right| \\
& \leq C h^{2} \sum_{T_{i} \in K_{2}}\|u\|_{H^{2}\left(T_{i}\right)} \cdot \sqrt{\left|T_{i}\right|} \cdot\left|w_{h}\right| \\
& \leq C h^{2}\|u\|_{H^{2}(\Omega)} \cdot\left\|w_{h}\right\| .
\end{aligned}
$$

By using Theorem 3.1, we clearly see that

$$
\left(u_{I}-u_{h}, w_{h}\right) \leq\left\|u_{I}-u_{h}\right\| \cdot\left\|w_{h}\right\| \leq C h^{1+s}\left\|w_{h}\right\| .
$$

We apply the estimates (3.52)-(3.55), (3.41), and (3.49) in (3.39) to obtain the result (3.37). Similarly, we can apply the estimates (3.42), (3.50)-(3.51), and (3.37) in (3.40) to obtain the result (3.38).

Lemma 3.6. For $0<s \leq 1$, assume that $\boldsymbol{v} \in\left(H^{1+s}(\Omega)\right)^{2} \cap \boldsymbol{V}, w \in H^{2}(\Omega)$, and $w_{I}$ is the interpolation function of $w$ defined in (3.3). Then we have for some constant $C>0$ that

$$
\begin{aligned}
\left\|\boldsymbol{v}-\Pi_{h} \boldsymbol{v}\right\| & \leq C h^{1+s}\|\boldsymbol{v}\|_{H^{1+s}(\Omega)}, \quad 0<s \leq 1, \\
\left\|P_{h} w-w_{I}\right\| & \leq C h^{2}\|w\|_{H^{2}(\Omega)} .
\end{aligned}
$$

Proof. From [15], if $\boldsymbol{v} \in\left(H^{2}(\Omega)\right)^{2} \cap \boldsymbol{V}$ and $w \in H^{2}(\Omega)$, then we have

$$
\begin{aligned}
& \left\|\boldsymbol{v}-\Pi_{h} \boldsymbol{v}\right\| \mid \leq C h^{2}\|\boldsymbol{v}\|_{H^{2}(\Omega)}, \\
& \left\|P_{h} w-w_{I}\right\| \leq C h^{2}\|w\|_{H^{2}(\Omega)} .
\end{aligned}
$$

The estimate (3.56) can be proved by interpolation theory.

Corollary 3.1. Assume that the regularity conditions (2.5) and (3.6) hold. Let $(\boldsymbol{p}, y, \boldsymbol{q}, z, u) \in(\boldsymbol{V} \times W)^{2} \times U_{\text {ad }}$ be the exact solutions defined in (2.9)-(2.13) and $\left(\boldsymbol{p}_{h}, y_{h}, \boldsymbol{q}_{h}, z_{h}, u_{h}\right) \in\left(\boldsymbol{V}_{h} \times W_{h}\right)^{2} \times U_{h}$ be the exact solutions of (2.25)-(2.29). Then we have

$$
\begin{gathered}
\left\|\left|\boldsymbol{p}-\boldsymbol{p}_{h}\right|||+\right\|\left|y-y_{h}\right| \|_{0} \leq C h^{1+\min (s, 1 / 2)} \\
\left|\left\|\boldsymbol{q}-\boldsymbol{q}_{h}\left|\|+\| z-z_{h}\right|\right\|_{0} \leq C h^{1+\min (s, 1 / 2)},\right. \\
\|\| u-\left.u_{h}||\right|_{0} \leq C h^{1+s}
\end{gathered}
$$

for $0<s \leq 1$. 
Proof. First, the errors are decomposed as

$$
\begin{aligned}
& \boldsymbol{p}-\boldsymbol{p}_{h}=\left(\boldsymbol{p}-\Pi_{h} \boldsymbol{p}\right)+\left(\Pi_{h} \boldsymbol{p}-\boldsymbol{p}_{h}\right), \\
& y-y_{h}=\left(y-P_{h} y\right)+\left(P_{h} y-y_{h}\right), \\
& \boldsymbol{q}-\boldsymbol{q}_{h}=\left(\boldsymbol{q}-\Pi_{h} \boldsymbol{q}\right)+\left(\Pi_{h} \boldsymbol{q}-\boldsymbol{q}_{h}\right), \\
& z-z_{h}=\left(z-P_{h} z\right)+\left(P_{h} z-z_{h}\right),
\end{aligned}
$$

and note that

$$
\begin{aligned}
& \left\|\left|y-P_{h} y\|\|_{0}=\left\|\left|y_{I}-P_{h} y\left\|\left.\right|_{0}=\right\| y_{I}-P_{h} y \|,\right.\right.\right.\right. \\
& \left\|\left|z-P_{h} z\|\|_{0}=\left\||| z_{I}-P_{h} z \mid\right\|_{0}=\left\|z_{I}-P_{h} z\right\|,\right.\right. \\
& \left\|\left|u-u_{h}\right|\right\|_{0}=\left\|\left|u_{I}-u_{h}\right|\right\|_{0}=\left\|u_{I}-u_{h}\right\| .
\end{aligned}
$$

Then by Lemma 3.6 and Theorems 3.1 and 3.2 we can prove the results of (3.60)(3.62).

\section{Global $L^{2}$ Superconvergence by postprocessing}

In this section, we will apply a higher order interpolation postprocessing method presented by Lin and Yan 26] to obtain global superconvergence for the mixed finite element approximations. As by-products, these superconvergence results can be utilized to form a class of useful a posteriori error estimators to assess the accuracy of the mixed finite element solutions in applications for the optimal control problems considered in this paper.

We construct a larger rectangular elements partition $\mathcal{T}_{2 h}$, which is the coarse meshes of $\mathcal{T}_{h}$. That is, each element $\tau$ of $\mathcal{T}_{2 h}$ is composed of four neighboring rectangular elements of $\mathcal{T}_{h}$. Based on this coarse meshes, we denote $\boldsymbol{V}_{2 h} \times W_{2 h}$ to express the order $k=1$ Raviart-Thomas mixed finite element spaces:

$$
\begin{aligned}
& \boldsymbol{V}_{2 h}=\left\{\boldsymbol{v} \in \boldsymbol{V}: \quad \forall \tau \in \mathcal{T}_{2 h},\left.\boldsymbol{v}\right|_{\tau} \in Q_{2,1}(\tau) \times Q_{1,2}(\tau)\right\}, \\
& W_{2 h}=\left\{w \in W: \quad \forall \tau \in \mathcal{T}_{2 h},\left.w\right|_{\tau} \in Q_{1,1}(\tau)\right\},
\end{aligned}
$$

and the related Raviart-Thomas projection (see [14] and 31]):

$$
\Pi_{2 h} \times P_{2 h}: \boldsymbol{V} \times W \rightarrow \boldsymbol{V}_{2 h} \times W_{2 h},
$$

which satisfies the following properties [26]:

(i) $P_{2 h} P_{h}=P_{2 h}$ and $\left\|P_{2 h} w_{h}\right\| \leq C\left\|w_{h}\right\|$, for all $w_{h} \in W_{h}$.

(ii) $\Pi_{2 h} \Pi_{h}=\Pi_{2 h}$ and $\left\|\Pi_{2 h} \boldsymbol{v}_{h}\right\|_{\text {div }} \leq C\left\|\boldsymbol{v}_{h}\right\|_{\text {div }}$, for all $\boldsymbol{v}_{h} \in \boldsymbol{V}_{h}$.

By using the interpolation operators $\Pi_{2 h}$ and $P_{2 h}$ and their properties, we immediately obtain the following global superconvergence theorem.

Theorem 4.1. Assume that the regularity conditions (2.5) and (3.6) hold. Let $(\boldsymbol{p}, y, \boldsymbol{q}, z, u) \in(\boldsymbol{V} \times W)^{2} \times U_{\text {ad }}$ be the exact solutions defined in (2.9) -(2.13) and $\left(\boldsymbol{p}_{h}, y_{h}, \boldsymbol{q}_{h}, z_{h}, u_{h}\right) \in\left(\boldsymbol{V}_{h} \times W_{h}\right)^{2} \times U_{h}$ be the exact solutions of (2.25)-(2.29). Then we have

$$
\begin{aligned}
& \left\|\boldsymbol{p}-\Pi_{2 h} \boldsymbol{p}_{h}\right\|_{\mathrm{div}}+\left\|y-P_{2 h} y_{h}\right\| \leq C h^{1+\min (s, 1 / 2)}, \\
& \left\|\boldsymbol{q}-\Pi_{2 h} \boldsymbol{q}_{h}\right\|_{\mathrm{div}}+\left\|z-P_{2 h} z_{h}\right\| \leq C h^{1+\min (s, 1 / 2)},
\end{aligned}
$$

for $0<s \leq 1$. 
Proof. From property (i) of the operator $P_{2 h}$, we find that

$$
y-P_{2 h} y_{h}=y-P_{2 h} y+P_{2 h}\left(P_{h} y-y_{h}\right) .
$$

Therefore, it follows from the approximation property, property (i) of the operator $P_{2 h}$, and Theorem 3.2 that

$$
\left\|y-P_{2 h} y_{h}\right\| \leq\left\|y-P_{2 h} y\right\|+C\left\|P_{h} y-y_{h}\right\| \leq C h^{1+\min (s, 1 / 2)},
$$

which implies (4.1). Similarly, we can obtain (4.2).

Furthermore, by using Lemma 3.3, it is obvious to see that

Lemma 4.1. For any function $\tilde{u} \in U_{a d}$, let $(\boldsymbol{p}(\tilde{u}), y(\tilde{u}), \boldsymbol{q}(\tilde{u}), z(\tilde{u}))$ and $\left(\boldsymbol{p}_{h}(\tilde{u}), y_{h}(\tilde{u}), \boldsymbol{q}_{h}(\tilde{u}), z_{h}(\tilde{u})\right)$ be the solutions of (2.30)-(2.33) and (2.34)-(2.37), respectively, for the lowest order Raviart-Thomas mixed finite elements. If the regularity condition

$$
y(\tilde{u}), z(\tilde{u}) \in H^{1}(\Omega), \quad \boldsymbol{p}(\tilde{u}), \boldsymbol{q}(\tilde{u}) \in\left(H^{2}(\Omega)\right)^{2}
$$

holds, then we have

$$
\begin{aligned}
& \left\|p(\tilde{u})-P_{2 h} p_{h}(\tilde{u})\right\|+\left\|\boldsymbol{p}(\tilde{u})-\Pi_{2 h} \boldsymbol{p}_{h}(\tilde{u})\right\| \leq C h^{2}, \\
& \left\|z(\tilde{u})-P_{2 h} z_{h}(\tilde{u})\right\|+\left\|\boldsymbol{q}(\tilde{u})-\Pi_{2 h} \boldsymbol{q}_{h}(\tilde{u})\right\| \leq C h^{2} .
\end{aligned}
$$

Proof. For brevity, we only give the proof of (4.4). From property (i) of the operator $P_{2 h}$, we find that

$$
z(\tilde{u})-P_{2 h} z_{h}(\tilde{u})=z(\tilde{u})-P_{2 h} z(\tilde{u})+P_{2 h}\left(P_{h} z(\tilde{u})-z_{h}(\tilde{u})\right) .
$$

Therefore, it follows from the approximation property, property (i) of the operator $P_{2 h}$, and Lemma 3.3 that

$$
\left\|z(\tilde{u})-P_{2 h} z_{h}(\tilde{u})\right\| \leq\left\|z(\tilde{u})-P_{2 h} z(\tilde{u})\right\|+C\left\|P_{h} z(\tilde{u})-z_{h}(\tilde{u})\right\| \leq C h^{2},
$$

which implies (4.4).

Then, in order to improve the accuracy of the control approximation on a global scale, as in [30] we construct a postprocessing projection operator of the discrete co-state to the admissible set

$$
\hat{u}(x)=\Pi_{[a, b]}\left(-\frac{1}{\nu}\left(P_{2 h} z_{h}\left(u_{h}\right)\right)(x)\right),
$$

where $\Pi_{[a, b]}$ was defined in (2.14). Now, we can prove the following global superconvergence result.

Theorem 4.2. Assume that the regularity conditions (2.5) and (3.6) hold. Let $(\boldsymbol{p}, y, \boldsymbol{q}, z, u) \in(\boldsymbol{V} \times W)^{2} \times U_{a d}$ be the exact solutions defined in (2.9) -(2.13) and $\left(\boldsymbol{p}_{h}, y_{h}, \boldsymbol{q}_{h}, z_{h}, u_{h}\right) \in\left(\boldsymbol{V}_{h} \times W_{h}\right)^{2} \times U_{h}$ be the exact solutions of (2.25)-(2.29). Then we have

$$
\|u-\hat{u}\| \leq C h^{1+s}, \quad 0<s \leq 1 .
$$


Proof. We note that the projection $\Pi_{[a, b]}$ defined in (2.14) is Lipschitz continuous with constant 1 from $L^{2}(\Omega)$ to $L^{2}(\Omega)$. From (2.15) and (4.5), we obtain by the triangle inequality

$$
\begin{aligned}
\|u-\hat{u}\| \leq & C\left\|z-P_{2 h} z_{h}\right\| \\
\leq & C\left(\left\|z(u)-z\left(u_{I}\right)\right\|+\left\|z\left(u_{I}\right)-P_{2 h} z_{h}\left(u_{I}\right)\right\|\right. \\
& \left.+\left\|P_{2 h} z_{h}\left(u_{I}\right)-P_{2 h} z_{h}\left(u_{h}\right)\right\|\right) .
\end{aligned}
$$

We firstly apply Lemma 3.2 to obtain that

$$
\left\|z(u)-z\left(u_{I}\right)\right\| \leq C h^{2}|\ln h|^{1 / 2} .
$$

Then, from the approximation property of the operator $P_{2 h}$, property (i) of the operator $P_{2 h}$, and (3.31), we have

$$
\begin{aligned}
\left\|z\left(u_{I}\right)-P_{2 h} z_{h}\left(u_{I}\right)\right\| & \leq\left\|z\left(u_{I}\right)-P_{2 h} z\left(u_{I}\right)\right\|+\left\|P_{2 h} z\left(u_{I}\right)-P_{2 h} z_{h}\left(u_{I}\right)\right\| \\
& \leq C h^{2}\left\|z\left(u_{I}\right)\right\|_{H^{2}(\Omega)}+\left\|P_{2 h} P_{h} z\left(u_{I}\right)-P_{2 h} z_{h}\left(u_{I}\right)\right\| \\
& \leq C h^{2}\left\|z\left(u_{I}\right)\right\|_{H^{2}(\Omega)}+\left\|P_{h} z\left(u_{I}\right)-z_{h}\left(u_{I}\right)\right\| \\
& \leq C h^{1+s}\|z\|_{H^{2+s}(\Omega)} .
\end{aligned}
$$

Next, it remains to bound the third term of above inequality (4.7). By property (i), we have

$$
\left\|P_{2 h} z_{h}\left(u_{I}\right)-P_{2 h} z_{h}\left(u_{h}\right)\right\| \leq C\left\|z_{h}\left(u_{I}\right)-z_{h}\left(u_{h}\right)\right\| .
$$

Similar to the proof of Lemma 3.1, we use (2.34)-(2.37) to obtain the error equations

$$
\begin{aligned}
& \left(A^{-1}\left(\boldsymbol{p}_{h}\left(u_{I}\right)-\boldsymbol{p}_{h}\left(u_{h}\right)\right), \boldsymbol{v}_{h}\right)-\left(y_{h}\left(u_{I}\right)-y_{h}\left(u_{h}\right), \operatorname{div} \boldsymbol{v}_{h}\right)=0, \\
& \left(\operatorname{div}\left(\boldsymbol{p}_{h}\left(u_{I}\right)-\boldsymbol{p}_{h}\left(u_{h}\right)\right), w_{h}\right)+\left(a_{0}\left(y_{h}\left(u_{I}\right)-y_{h}\left(u_{h}\right)\right), w_{h}\right)=\left(u_{I}-u_{h}, w_{h}\right), \\
& \left(A^{-1}\left(\boldsymbol{q}_{h}\left(u_{I}\right)-\boldsymbol{q}_{h}\left(u_{h}\right)\right), \boldsymbol{v}_{h}\right)-\left(z_{h}\left(u_{I}\right)-z_{h}\left(u_{h}\right), \operatorname{div} \boldsymbol{v}_{h}\right)=-\left(\boldsymbol{p}_{h}\left(u_{I}\right)-\boldsymbol{p}_{h}\left(u_{h}\right), \boldsymbol{v}_{h}\right), \\
& \left(\operatorname{div}\left(\boldsymbol{q}_{h}\left(u_{I}\right)-\boldsymbol{q}_{h}\left(u_{h}\right)\right), w_{h}\right)+\left(a_{0}\left(z_{h}\left(u_{I}\right)-z_{h}\left(u_{h}\right)\right), w_{h}\right)=\left(y_{h}\left(u_{I}\right)-y_{h}\left(u_{h}\right), w_{h}\right),
\end{aligned}
$$

for all $\boldsymbol{v}_{h} \in \boldsymbol{V}_{h}$ and $w_{h} \in W_{h}$. We use the stability property of the saddle-point problem to obtain that

$$
\begin{aligned}
& \left\|z_{h}\left(u_{I}\right)-z_{h}\left(u_{h}\right)\right\|+\left\|\boldsymbol{q}_{h}\left(u_{I}\right)-\boldsymbol{q}_{h}\left(u_{h}\right)\right\| \\
& \quad \leq C\left(\left\|y_{h}\left(u_{I}\right)-y_{h}\left(u_{h}\right)\right\|+\left\|\boldsymbol{p}_{h}\left(u_{I}\right)-\boldsymbol{p}_{h}\left(u_{h}\right)\right\|\right) \\
& \quad \leq C\left\|u_{I}-u_{h}\right\| \leq C h^{1+s},
\end{aligned}
$$

where the last step was derived by using Theorem 3.1 .

Finally, we have established (4.6) from (4.7) combined with (4.8)-(4.11).

It is of great importance for a mixed finite element method to have a computable a posteriori error estimator by which we can evaluate the accuracy of the mixed finite element solutions in applications. One way to construct error estimators is to employ certain superconvergence properties of the finite element solutions. Thus, based on the above global superconvergence, we can obtain the following recovery type a posteriori error estimates for the control problems.

Theorem 4.3. Assume that the regularity conditions (2.5) and (3.6) hold. Let $(\boldsymbol{p}, y, \boldsymbol{q}, z, u) \in(\boldsymbol{V} \times W)^{2} \times U_{a d}$ be the exact solutions defined in (2.9) $-(2.13)$ and 
$\left(\boldsymbol{p}_{h}, y_{h}, \boldsymbol{q}_{h}, z_{h}, u_{h}\right) \in\left(\boldsymbol{V}_{h} \times W_{h}\right)^{2} \times U_{h}$ be the exact solutions of (2.25)-(2.29). Then we have

$$
\begin{aligned}
& \left\|\boldsymbol{p}-\boldsymbol{p}_{h}\right\|_{\text {div }}=\left\|\Pi_{2 h} \boldsymbol{p}_{h}-\boldsymbol{p}_{h}\right\|_{\text {div }}+O\left(h^{1+\min (s, 1 / 2)}\right), \\
& \left\|y-y_{h}\right\|=\left\|P_{2 h} y_{h}-y_{h}\right\|+O\left(h^{1+\min (s, 1 / 2)}\right), \\
& \left\|\boldsymbol{q}-\boldsymbol{q}_{h}\right\|_{\text {div }}=\left\|\Pi_{2 h} \boldsymbol{q}_{h}-\boldsymbol{q}_{h}\right\|_{\text {div }}+O\left(h^{1+\min (s, 1 / 2)}\right), \\
& \left\|z-z_{h}\right\|=\left\|P_{2 h} z_{h}-z_{h}\right\|+O\left(h^{1+\min (s, 1 / 2)}\right), \\
& \left\|u-u_{h}\right\|=\left\|\hat{u}-u_{h}\right\|+O\left(h^{1+s}\right),
\end{aligned}
$$

for $0<s \leq 1$. Furthermore, there hold

$$
\begin{aligned}
& \lim _{h \rightarrow 0} \frac{\left\|\Pi_{2 h} \boldsymbol{p}_{h}-\boldsymbol{p}_{h}\right\|_{\text {div }}}{\left\|\boldsymbol{p}-\boldsymbol{p}_{h}\right\|_{\text {div }}}=1, \\
& \lim _{h \rightarrow 0} \frac{\left\|P_{2 h} y_{h}-y_{h}\right\|}{\left\|y-y_{h}\right\|}=1, \\
& \lim _{h \rightarrow 0} \frac{\left\|\Pi_{2 h} \boldsymbol{q}_{h}-\boldsymbol{q}_{h}\right\|_{\text {div }}}{\left\|\boldsymbol{q}-\boldsymbol{q}_{h}\right\|_{\text {div }}}=1, \\
& \lim _{h \rightarrow 0} \frac{\left\|P_{2 h} z_{h}-z_{h}\right\|}{\left\|z-z_{h}\right\|}=1, \\
& \lim _{h \rightarrow 0} \frac{\left\|\hat{u}-u_{h}\right\|}{\left\|u-u_{h}\right\|}=1 .
\end{aligned}
$$

Proof. The proof follows easily from Theorems 4.144.2 and the composed relations as follows:

$$
\begin{aligned}
& \boldsymbol{p}-\boldsymbol{p}_{h}=\left(\Pi_{2 h} \boldsymbol{p}_{h}-\boldsymbol{p}_{h}\right)+\left(\boldsymbol{p}-\Pi_{2 h} \boldsymbol{p}_{h}\right), \\
& y-y_{h}=\left(P_{2 h} y_{h}-y_{h}\right)+\left(y-P_{2 h} y_{h}\right), \\
& \boldsymbol{q}-\boldsymbol{q}_{h}=\left(\Pi_{2 h} \boldsymbol{q}_{h}-\boldsymbol{q}_{h}\right)+\left(\boldsymbol{q}-\Pi_{2 h} \boldsymbol{q}_{h}\right), \\
& z-z_{h}=\left(P_{2 h} z_{h}-z_{h}\right)+\left(z-P_{2 h} z_{h}\right), \\
& u-u_{h}=\left(\hat{u}-u_{h}\right)+(u-\hat{u}) .
\end{aligned}
$$

Therefore, the recovery type a posteriori error estimators defined above are asymptotically exact if the conditions for superconvergence are valid.

\section{Numerical tests}

We present below two examples to illustrate the superconvergence theoretical results of the control. In both cases, the Laplace operator $-\Delta$ was chosen for the elliptic operator $A(x)$. The first example is based on Example 1 of [30] with some modification. In the second example, we take the obstacle function not as a constant, but with some weak discontinuities, and find the same superconvergence phenomenon in the first example.

Actually, our numerical example satisfies the stronger regularity $y, z \in H^{3}(\Omega)$. The numerical results will show that the approximated solution of the control possesses almost two order superconvergences for the approximation space of piecewise constant functions.

Both optimization problems were solved numerically by projected gradient methods, with codes developed based on AFEPack [24]. The discretization was already 
described in previous sections: The control function $u$ is discretized by piecewise constant functions, whereas the state $(y, \boldsymbol{p})$ and the co-state $(z, \boldsymbol{q})$ were approximated by the lowest order Raviart-Thomas mixed finite element functions. In our examples, we choose the domain $\Omega=[0,1] \times[0,1]$. We use the uniform rectangle partitions.

Example 1. We consider the following two dimensional elliptic optimal control problem:

$$
\min _{u \in U_{a d}}\left\{\frac{1}{2}\left\|\boldsymbol{p}-\boldsymbol{p}_{d}\right\|^{2}+\frac{1}{2}\left\|y-y_{d}\right\|^{2}+\frac{\nu}{2}\|u\|^{2}\right\}
$$

subject to the state equation

$$
\operatorname{div} \boldsymbol{p}+a_{0} y=u+f, \quad \boldsymbol{p}=-A(x) \operatorname{grad} y, \quad x \in \Omega,
$$

which is written in the form of the first order system with the boundary condition

$$
y=0, \quad x \in \partial \Omega,
$$

where $\Omega=[0,1] \times[0,1]$. Here we choose $A(x) \equiv 1$ and $a_{0} \equiv 0$. Then the state equation may be restated as

$$
\operatorname{div} \boldsymbol{p}=u+f, \quad \boldsymbol{p}=-\operatorname{grad} y, \quad x \in \Omega .
$$

Next, we introduce the co-state elliptic equation

$$
\operatorname{div} \boldsymbol{q}=y-y_{d}, \quad \boldsymbol{q}=-\left(\operatorname{grad} z+\boldsymbol{p}-\boldsymbol{p}_{d}\right), \quad x \in \Omega,
$$

with the boundary condition

$$
z=0, \quad x \in \partial \Omega .
$$

Now, we define the optimal state function by

$$
y\left(x_{1}, x_{2}\right)=\sin \left(\pi x_{1}\right) \sin \left(\pi x_{2}\right)
$$

and the source function $f$ is given by

$$
f\left(x_{1}, x_{2}\right)= \begin{cases}u_{f}\left(x_{1}, x_{2}\right)-a, & \text { if } u_{f}\left(x_{1}, x_{2}\right)<a \\ 0, & \text { if } u_{f}\left(x_{1}, x_{2}\right) \in[a, b] \\ u_{f}\left(x_{1}, x_{2}\right)-b, & \text { if } u_{f}\left(x_{1}, x_{2}\right)>b\end{cases}
$$

with $u_{f}\left(x_{1}, x_{2}\right)=2 \pi^{2} \sin \left(\pi x_{1}\right) \sin \left(\pi x_{2}\right)$. Due to the state equation (5.4), we obtain for the exact optimal control function $u$

$$
u\left(x_{1}, x_{2}\right)= \begin{cases}a, & \text { if } u_{f}\left(x_{1}, x_{2}\right)<a, \\ u_{f}\left(x_{1}, x_{2}\right), & \text { if } u_{f}\left(x_{1}, x_{2}\right) \in[a, b], \\ b, & \text { if } u_{f}\left(x_{1}, x_{2}\right)>b .\end{cases}
$$

For the optimal co-state function $z$, we find

$$
z\left(x_{1}, x_{2}\right)=-2 \pi^{2} \nu \sin \left(\pi x_{1}\right) \sin \left(\pi x_{2}\right) .
$$

It follows from the co-state equation (5.5) that

$$
y-y_{d}=-\operatorname{div}\left(\operatorname{grad} z+\boldsymbol{p}-\boldsymbol{p}_{d}\right)=-4 \pi^{4} \nu \sin \left(\pi x_{1}\right) \sin \left(\pi x_{2}\right)-\operatorname{div}\left(\boldsymbol{p}-\boldsymbol{p}_{d}\right)
$$

or

$$
\operatorname{div} \boldsymbol{p}_{d}+y_{d}=y+u+f+4 \pi^{4} \nu \sin \left(\pi x_{1}\right) \sin \left(\pi x_{2}\right) .
$$

Thus, the desired state variables are given by

$$
y_{d}\left(x_{1}, x_{2}\right)=y+2 \pi^{4} \nu \sin \left(\pi x_{1}\right) \sin \left(\pi x_{2}\right)=\left(1+2 \pi^{4} \nu\right) \sin \left(\pi x_{1}\right) \sin \left(\pi x_{2}\right)
$$




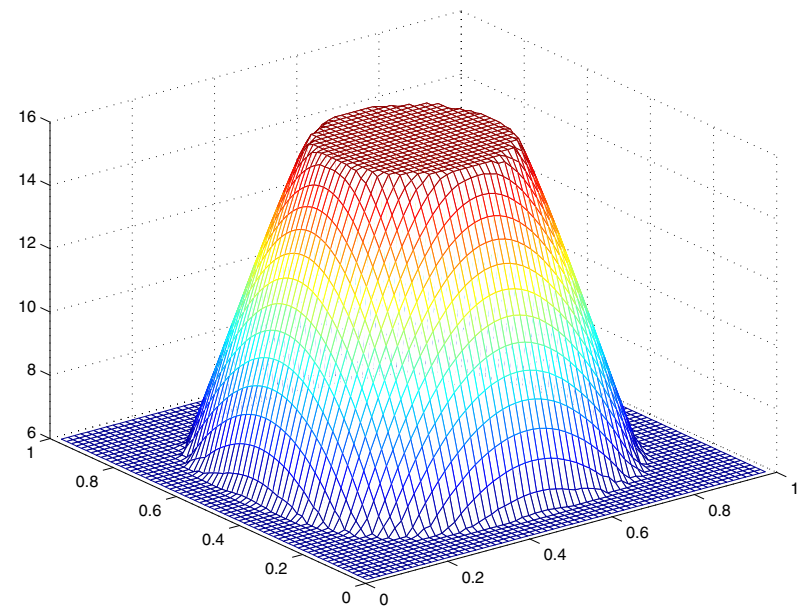

Figure 1. The profile of the numerical solution of Example 1 on the $64 \times 64$ mesh grid.

and

$\operatorname{div} \boldsymbol{p}_{d}=u+f+2 \pi^{4} \nu \sin \left(\pi x_{1}\right) \sin \left(\pi x_{2}\right)=-\operatorname{div}\left(\operatorname{grad}\left(y-\pi^{2} \nu \sin \left(\pi x_{1}\right) \sin \left(\pi x_{2}\right)\right)\right)$.

We may choose

$$
\begin{aligned}
\boldsymbol{p}_{d}\left(x_{1}, x_{2}\right) & =-\operatorname{grad}\left(y-\pi^{2} \nu \sin \left(\pi x_{1}\right) \sin \left(\pi x_{2}\right)\right) \\
& =\left(-\left(\pi-\pi^{3} \nu\right) \cos \left(\pi x_{1}\right) \sin \left(\pi x_{2}\right),-\left(\pi-\pi^{3} \nu\right) \sin \left(\pi x_{1}\right) \cos \left(\pi x_{2}\right)\right) .
\end{aligned}
$$

In numerical implementation, we set $a=6$ and $b=16$ to make both the lower and the upper constraints active. The profile of the numerical solution is plotted in Figure 1 and the error $\left\|u_{I}-u_{h}\right\|$ and $\|u-\hat{u}\|$ obtained on a sequence of uniformly refined meshes are presented in Table 1 . The superconvergence phenomenon can clearly be observed from the data.

\begin{tabular}{||c|c|c||c|c||}
\hline \hline resolution & $\left\|u_{I}-u_{h}\right\|$ & order & $\|u-\hat{u}\|$ & order \\
\hline $16 \times 16$ & $3.239 \mathrm{e}-02$ & - & $1.494 \mathrm{e}-01$ & - \\
\hline $32 \times 32$ & $8.457 \mathrm{e}-03$ & 1.94 & $3.763 \mathrm{e}-02$ & 1.99 \\
\hline $64 \times 64$ & $2.058 \mathrm{e}-03$ & 2.04 & $9.387 \mathrm{e}-03$ & 2.00 \\
\hline $128 \times 128$ & $5.218 \mathrm{e}-04$ & 1.98 & $2.354 \mathrm{e}-03$ & 2.00 \\
\hline \hline
\end{tabular}

TABLE 1. The error of the numerical solution of Example 1 on a sequence of uniformly refined mesh grid.

Example 2. In this example, we investigate the case of the nonconstant control constraints. We replace $a$ and $b$ in Example 1 by two specific functions as follows:

$$
\begin{aligned}
& a\left(x_{1}, x_{2}\right)=5+\frac{5}{\sqrt{2}}\left|x_{1}-x_{2}\right|, \\
& b\left(x_{1}, x_{2}\right)=10+\frac{8}{\sqrt{2}}\left|x_{1}+x_{2}-1\right| .
\end{aligned}
$$




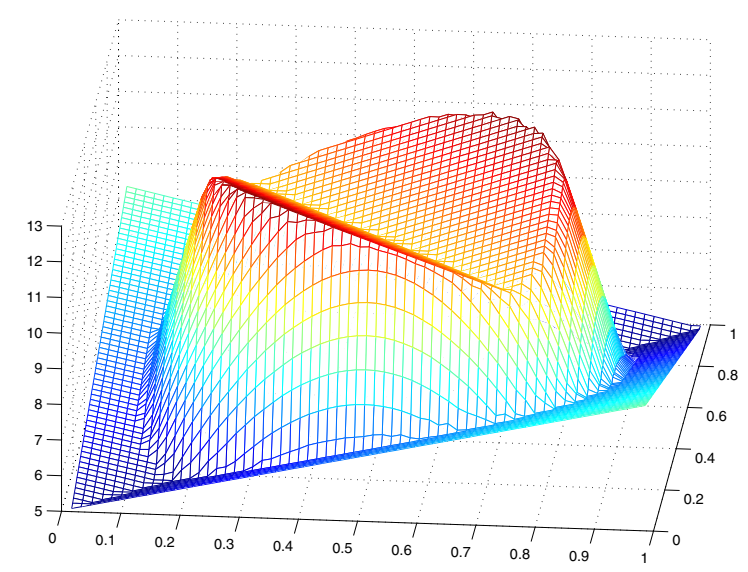

Figure 2. The profile of the numerical solution of Example 2 on the $64 \times 64$ mesh grids.

Then not only the constraints depend on the coordinates $\left(x_{1}, x_{2}\right)$, but also there are some weak discontinuities in both constraints. The profile of the numerical solution is presented in Figure 2, From the error data on the uniformly refined meshes, as listed in Table 2, it can be seen that the superconvergence remains, even though there is the introduction of the weak discontinuities in the input data.

\begin{tabular}{||c|c|c||c|c||}
\hline \hline resolution & $\left\|u_{I}-u_{h}\right\|$ & order & $\|u-\hat{u}\|$ & order \\
\hline $16 \times 16$ & $1.995 \mathrm{e}-02$ & - & $9.109 \mathrm{e}-02$ & - \\
\hline $32 \times 32$ & $5.056 \mathrm{e}-03$ & 1.98 & $2.289 \mathrm{e}-02$ & 1.99 \\
\hline $64 \times 64$ & $1.261 \mathrm{e}-03$ & 2.00 & $5.712 \mathrm{e}-03$ & 2.00 \\
\hline $128 \times 128$ & $3.205 \mathrm{e}-04$ & 1.98 & $1.435 \mathrm{e}-03$ & 1.99 \\
\hline \hline
\end{tabular}

TABLE 2. The error of the numerical solution of Example 2 on a sequential of uniformly refined mesh grids.

\section{Conclusion And Future WORK}

The present paper discussed the rectangular lowest order Raviart-Thomas mixed finite element methods for the optimal control problem (1.1)-(1.3). By applying the superconvergence results (see [15] and [16]) of standard mixed finite element methods, we have established some local and global superconvergence results in $L^{2}$ norm both for the state and the co-state discrete solutions with convergence order $\left.h^{1+\min (s, 1 / 2)}\right)$, and for the control approximation with convergence order $h^{1+s}$, where $0<s \leq 1$.

These results can be extended to mixed finite element methods on quadrilaterals. Moreover, one may consider the piecewise point behavior of the approximations and $L^{\infty}$-norm superconvergence properties for the flux functions along the Gauss lines and for the scalar functions at the Gauss points. We have used piecewise constant 
functions to approximate the control variable. In our future work, we shall use the standard linear element space to approximate the control function.

Furthermore, we shall investigate the case that $a$ and $b$ in the admissible control set $U_{a d}$ are some smooth functions (not constants, as in the present paper; see (1.4)) or the set

$$
U_{a d}=\left\{u \in L^{2}(\Omega): \quad \int_{\Omega} u(x) d x \geq 0\right\} .
$$

\section{ACKNOWLEDGMENTS}

This paper was finished while the author visited Hong Kong Baptist University. The author is grateful to the referees for their helpful suggestions and comments, and also thanks Professor Ruo Li for assistance in the numerical work.

\section{REFERENCES}

[1] R. A. Adams, Sobolev Spaces, Academic Press, New York, San Francisco, London, 1975. MR0450957 (56:9247)

[2] N. Arada, E. Casas, and F. Troltzsch, Error estimates for a semilinear elliptic control problem, Computational Optimization and Applications, 23 (2002), pp. 201-229. MR 1937089 (2003k:65140)

[3] C. Bacuta, J. H. Bramble, and J. XU, Regularity estimates for elliptic boundary value problems with smooth data on polygonal domains, Numerische Mathematik, 11 (2003), pp. 75-94. MR1987589 (2004d:35027)

[4] J. Bergh, J. LÖFström, Interpolation Spaces, An Introduction, Springer, Berlin, 1976. MR0482275 (58:2349)

[5] J. H. Bramble and J. Xu, Some estimates for a weighted $L^{2}$ projection, Math. Comp., 56 (1991), pp. 463-476. MR1066830 (91k:65140)

[6] J. H. BRAndTS, Superconvergence and a posteriori error estimation for triangular mixed finite elements, Numer. Math., 68 (1994), no. 3, pp. 311-324. MR1313147 (96a:65162)

[7] F. Brezzi and M. Fortin, Mixed and Hybrid Finite Element Methods, Springer-Verlag, 1991. MR 92d:65187 MR.1115205 (92d:65187)

[8] E. Casas and L. A. Fernández, Optimal control of semilinear elliptic equations with pointwise constraints on the gradient of the state, Appl. Math. Optim., 27 (1993), pp. 35-56. MR.1183301 (93h:49012)

[9] Y. Chen and W. B. Liu, Posteriori error estimates for mixed finite elements of a quadratic control problem, Recent Progress in Computational and Applied PDEs, Kluwer Academic, 2002, pp. 123-134.

[10] Y. Chen and W. B. Liu, Error estimates and superconvergence of mixed finite element for quadratic optimal control, International J. Numerical Analysis and Modeling, 3 (2006), no. 3, pp. 311-321. MR2237885 (2007c:49036)

[11] Y. Chen and W. B. Liu, A posteriori error estimates for mixed finite element solutions of convex optimal control problems, Journal of Computational and Applied Mathematics, in press.

[12] P. G. Ciarlet, The Finite Element Method for Elliptic Problems, North-Holland, Amsterdam, 1978. MR0520174 (58:25001)

[13] M. Dauge, S. Nicaise, M. Bourland, and M.S. Lubuma, Coefficients of the singularities for elliptic boundary value problems on domains with conical points III: Finite Element Methods on Polygonal Domains, SIAM J. Numer. Anal., 29, no. 1, 1992, pp. 136-155. MR1149089 (93a:65146)

[14] J. Douglas, JR. And J. E. Roberts, Global estimates for mixed finite element methods for second order elliptic equations, Math. Comp. 44 (1985), pp. 39-52. MR771029 (86b:65122)

[15] R. E. Ewing, R. Lazarov, And J. Wang, Superconvergence for the Velocity Along the Gauss Lines in Mixed Finite Element Methods, SIAM J. Numer. Anal., 28 (1991), pp. 1015-1029. MR:1111451 (92e:65149) 
[16] R. E. Ewing, M. Liu, AND J. WAng, Superconvergence of mixed finite element approximations over quadrilaterals, SIAM J. Numer. Anal., 36 (1999), pp. 772-787. MR1681041 (2000c:65102)

[17] F. S. FALK, Approximation of a class of optimal control problems with order of convergence estimates, J. Math. Anal. Appl., 44 (1973), pp. 28-47. MR0686788 (58:33347)

[18] T. GEveCI, On the approximation of the solution of an optimal control problem governed by an elliptic equation, RAIRO Anal. Numer., 13 (1979), pp. 313-328. MR555382 (80j:93060)

[19] Y. Huang, Finite element Method - Extrapolations and Superconvergence, Ph.D thesis, Institute of System Science and Mathematics Science, April, 1987.

[20] Y. HuANG AND Q. Lin, Finite element methods and extrapolations on polygonal domains, Numer. Math. Sinica, Vol. 12, no. 3, 1990, pp. 239-249. MR.1217895 (94c:65138)

[21] Y. HuAng AND Q. Lin, Elliptic boundary value problems and finite element method approximations on polygonal domains, J. Sys. Sci. \& Math. Sci., 12, no. 3, 1992, pp. 263-268. MR.1217895 (94c:65138)

[22] Y. HUANG AND Q. LIN, Green's function and some estimate of F.E.M. approximations on polygonal domains, J. Sys. Sci. \& Math. Sci., 14, no. 1, 1994, pp. 1-8. MR.1331525|(96c:65181)

[23] Y. KWON AND F. A. MilneR, $L^{\infty}$-error estimates for mixed methods for semilinear secondorder elliptic equations, SIAM J. Numer. Anal., 25 (1988), pp. 46-53. MR923925|(89c:65122)

[24] R. LI, W. B. LiU, http://circus.math.pku.edu.cn/AFEPack.

[25] R. LI, H. MA, W. B. LIU, AND T. TANG, Adaptive finite element approximation for distributed elliptic optimal control problems, SIAM J. Control and Optimization, 41 (2002), pp. 13211349. MR1971952 (2004a:49036)

[26] Q. Lin, N. N. Yan, Structure and Analysis for Efficient Finite Element Methods, Publishers of Hebei University, in Chinese, 1996.

[27] J. L. Lions, Optimal Control of Systems Governed by Partial Differential Equations, Springer-Verlag, Berlin, 1971. MR0271512 (42:6395)

[28] W. B. LIU AND N. N. YAN, A posteriori error estimates for optimal boundary control, SIAM J. Numer. Anal., 39 (2001), pp. 73-99. MR1860717 (2002j:49040)

[29] W. B. LIU AND N. N. YAN, A posteriori error estimates for control problems governed by Stokes' equations, SIAM J. Numer. Anal., 40 (2003), pp. 1805-1869. MR1950625 (2003j:65119)

[30] C. MEYER AND A. RÖSCH, Superconvergence properties of optimal control problems, SIAM Journal on Control and Optimization, 43 (2004) (3), pp. 970-985. MR2114385 (2005i:49024)

[31] P. A. Raviart and J. M. Thomas, A mixed finite element method for 2nd order elliptic problems, Mathematical Aspects of the Finite Element Method, Lecture Notes in Mathematics, vol. 606, Springer-Verlag, New York, 1977, pp. 292-315. MR0483555 (58:3547)

[32] D. Tiba And F. Troltzsch, Error estimates for the discretization of state constrained convex control problems, Numer. Funct. Anal. Optim., 17 (1996), pp. 1005-1028. MR1421304 (97h:49046)

[33] N. YAN, Superconvergence and recovery type a posteriori error estimate for constrained convex optimal control problems, Advances in Scientific Computing and Applications (Y. Lu, W. Sun and T. Tang, ed.), Science Press, Beijing/New York (2004), 408-419.

Hunan Key Laboratory for Computation and Simulation in Science and Engineering, Department of Mathematics, Xiangtan University, Xiangtan 411105, Hunan, China

E-mail address: ypchen@xtu.edu.cn 